\title{
La renovación de la arquitectura eclesiástica en el siglo XX-XXI latinoamericano
}

The renewal of church architecture in the Latin American XX-XXI century

Fernando Pérez Oyarzun · Pontificia Universidad Católica de Chile (Santiago de Chile)

https://doi.org/10.17979/aarc.2015.4.0.5116

\section{RESUMEN}

Los cambios que sufren las iglesias católicas —y más en general, una porción muy significativa de los edificios religiosos durante el siglo XX — son fruto de un complejo encuentro entre la radical renovación que se lleva a cabo en la arquitectura moderna, como una de las respuestas al complejo proceso de renovación de nuestra cultura, y los cambios producidos al interior de la Iglesia Católica, incluyendo una nueva consciencia teológica, una nueva interpretación de las fuentes bíblicas, y significativas modificaciones en la praxis religiosa que expresa una relación nueva entre la fe y el mundo. Ciertamente, el Concilio Vaticano II constituye un episodio fundamental en este último proceso. Es en este contexto que me propongo examinar algunos rasgos específicos de esa renovación de la arquitectura sacra en América Latina.

\section{PALABRAS CLAVE}

Latinoamérica, arquitectura religiosa contemporánea, siglos XX-XXI, Concilio Vaticano II.

\section{ABSTRACT}

Changes suffering Catholic churches-and more generally, a significant portion of religious buildings during the twentieth century are the result of a complex encounter between the radical renewal takes place in modern architecture, as one of the answers to the complex process of renewal of our culture, and the changes within the Catholic Church, including a new theological consciousness, a new interpretation of the biblical sources, and significant changes in religious practice that expresses a new relationship between faith and the world. Certainly Vatican II is a key episode in the latter process. It is in this context that I propose to examine some specific features of the renewal of sacred architecture in Latin America.

\section{KEYWORDS}

Latin America, Contemporary Religious Architecture, XX-XXI centuries, Second Vatican Council. 


\section{INTRODUCCION}

Es frecuente analizar los cambios en la concepción y construcción de iglesias durante el siglo XX, tomando como eje temporal el Concilio Vaticano II y su transcendental reforma a la Sagrada Liturgia. La condición de preconciliar y postconciliar se constituyen así en categorías básicas de análisis respecto de la arquitectura eclesiástica. Ello, especialmente cuando ésta se analiza no sólo desde el punto de vista de la historia y la crítica de arquitectura, sino tomando en consideración su rol en la vida de la Iglesia.

Sin desconocer la importancia fundamental del Concilio en ésta y otras materias, así como la marca indeleble que ha dejado en la Iglesia del siglo XX -a su manera prolongado hasta hoy mismo--, se propone aquí una perspectiva de análisis diversa. Para ello será necesario abrir más el foco analítico, tanto en el arco temporal como en los factores considerados.

Los cambios que sufren las iglesias católicas $-\mathrm{y}$ más en general, una porción muy significativa de los edificios religiosos durante el siglo XX - son fruto de un complejo encuentro entre la radical renovación que se lleva a cabo en la arquitectura moderna, como una de las respuestas al complejo proceso de renovación de nuestra cultura, y los cambios producidos al interior de la Iglesia Católica, incluyendo una nueva consciencia teológica, una nueva interpretación de las fuentes bíblicas, y significativas modificaciones en la praxis religiosa que expresa una relación nueva entre la fe y el mundo. Ciertamente, el Concilio Vaticano II constituye un episodio fundamental en este último proceso.

Tomando este hecho en consideración y llevando esta idea aún más lejos, quisiera proponer que incluso desde un punto de vista intraeclesial, no deberíamos considerar el impacto del Concilio Vaticano II sobre la construcción de iglesias sólo en términos de la reforma litúrgica. Sin duda éste es un aspecto fundamental. Sin embargo, la cuestión debería ser pensada de manera más integral, dentro del espíritu del Concilio y de los desafíos que debe enfrentar la Iglesia en el ámbito de la cultura contemporánea.

Por otra parte, el Concilio no puede verse sólo como un hecho aislado, después del cual todo cambió. Él actúa más bien como detonante de un complejo proceso de reflexión y de cambio, cuyo impacto aún estamos viviendo. Bastaría recordar lo que fueron las Conferencias Generales del Episcopado Latinoamericano de
Medellín o Puebla para comprender cómo las conclusiones conciliares continuaron siendo elaboradas e interpretadas en la realidad Latinoamericana, a poco de haber sido formuladas.

Es en este contexto que me propongo examinar algunos rasgos específicos de esa renovación de la arquitectura sacra en América Latina. La iglesia latinoamericana recibe y protagoniza, a su modo, tanto los procesos de modernización del siglo XX como sus consecuencias al interior de la Iglesia, siendo fundamentales algunas de las reflexiones y consecuentes documentos que se producen en ella con posterioridad al Concilio. Este análisis se realiza menos desde la idea de logro que desde el intento por inventariar un conjunto de problemas que durante el siglo XX y el comienzo del $\mathrm{XXI}$, la arquitectura religiosa ha debido enfrentar.

\section{EL MOVIMIENTO LITURGICO Y EL ARTE DE VANGUARDIA}

Algunos de los ejemplos más notables de iglesias católicas construidas durante el siglo XX son resultado de un fructífero encuentro entre las exploraciones del arte y la cultura de vanguardia de comienzos de siglo, con la renovación del culto que venía incubándose en la Iglesia desde fines del siglo XIX. En este sentido, debe recordarse que el retorno al contacto y el diálogo con los artistas preocuparon tanto a los papas Pablo VI como Juan Pablo II.

Este encuentro significó, por una parte, la apertura y el interés de destacados pensadores de la Iglesia por el arte moderno, específicamente por las posibilidades que éste ofrecía de renovar la expresión de los misterios de la Iglesia. Recordemos al respecto la relación de Le Corbusier con el padre Couturier, que posibilitó el surgimiento de obras como la capilla de Ronchamp o el convento de La Tourette. Por otra parte, hay que destacar también el interés de algunos de los maestros de la arquitectura moderna por explorar las posibilidades que los nuevos lenguajes arquitectónicos ofrecían para tratar temas clásicos como el del templo. Algunos de estos maestros $-\mathrm{y}$ le Corbusier ha sido explícito al respecto- se manifestaron atraídos por el misterio de lo sagrado, a pesar de su condición de no creyentes.

Deben mencionarse también fenómenos paralelos, como el de la reconstrucción posterior a la Segunda Guerra Mundial, que obligaron a una construcción relativamente masiva de iglesias, proporcionando una 

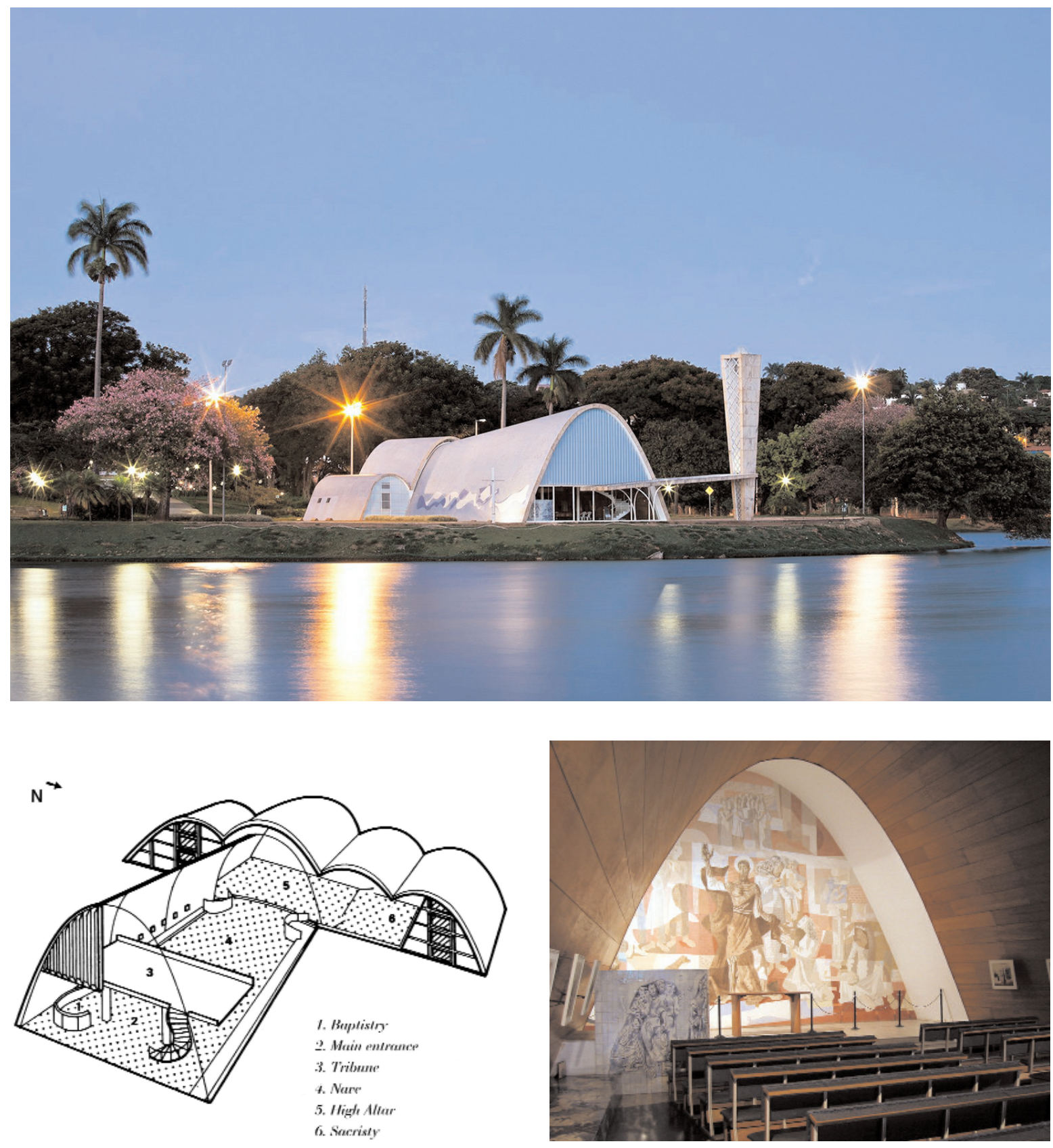

Fig. 01. Oscar Niemeyer, San Francisco, Pampulha (Minas Gerais, Brasil), 1940/43. 
oportunidad inédita de probar nuevas alternativas en la edificación de espacios de culto.

Este conjunto de fenómenos define un momento cultural que dio como resultado, no sólo algunas de las más notables obras del siglo XX, sino también una reflexión que se manifiesta en publicaciones significativas, como las revistas Art Chretien o L'art d'Eglise, y en una síntesis como la realizada por el arquitecto Rudolf Schwarz, como se sabe, muy cercano a Romano Guardini, en su libro Vom Bau der Kirche, publicado por primera vez en 1938, y una década más tarde en inglés como The Church Incarnate. Los diseños de dom Hans van der Laan, tanto de iglesias como de ornamentos y muebles sagrados, pueden ser inscritos dentro de esta misma corriente, en la que disposiciones como el altar de cara al pueblo rodeado de la congregación, anticiparían algunas de las propuestas del Concilio.

\section{ECOS DE LA RENOVACION EN LATINOAMERICA}

Los ecos de la reforma que se venía gestando al interior de la Iglesia Católica a mediados del siglo XX llegan a Latinoamérica por variadas vías: órdenes monásticas como la de los benedictinos, teólogos y liturgistas formados en Europa, etc. Como en otras latitudes, atrae también a una cantidad significativa de arquitectos que ven la oportunidad de renovar el lenguaje de la arquitectura sacra o de hacer coincidir su propios intereses profesionales con uno de los temas clásicos de la historia de la arquitectura. Los mejores ejemplos se producen entre los años de la posguerra y mediados de los años sesenta, coincidiendo con la promulgación de las normas conciliares sobre la nueva liturgia.

La nueva liturgia no es sólo una nueva forma ritual. Ella es, sobre todo, la expresión de una nueva espiritualidad; y es dicha espiritualidad la que se expresa en la mejor arquitectura eclesiástica. Sin embargo, liturgia y espiritualidad deben cruzarse con una serie de procesos culturales, artísticos y específicamente arquitectónicos que ocurren en esos mismos años, para comprender mejor sus resultados arquitectónicos.

Realizada entre 1940 y 1943, la iglesia de San Francisco en Pampulha (Brasil), ha llegado a ser una de las obras clásicas de Oscar Niemeyer (Fig. 01). La iglesia forma parte del equipamiento de una nueva urbanización en las afueras de Belo Horizonte, realizada alrededor de un lago artificial. Ella constituye a la vez una innovación radical y la reinterpretación de una tipología clásica: la iglesia de campanario aislado. Oscar Niemeyer asume la nueva sensibilidad en construcción de iglesias a pesar de su relativa lejanía de la Iglesia. La novedad de su propuesta se acentúa si tenemos en cuenta que ella es anterior a iglesias clásicas del Movimiento Moderno, como Ronchamp y La Tourette.

$\mathrm{Al}$ menos tres elementos deben tenerse en cuenta al analizarla:

En primer lugar la cuestión estructural: la exploración de las bóvedas-cáscaras parabólicas como tipo estructural, asocia la arquitectura de los templos al problema de salvar una luz favoreciendo la opción de una nave única, como dispositivo capaz de mejor congregar la asamblea alrededor del altar. Al mismo tiempo, vincula Pampulha a una generación de iglesias y otras construcciones que harían uso de las bóvedas-cáscaras en Latinoamérica.

A través de la masiva inclusión de mosaicos de Cándido Portinari, se continúa la tendencia a la incorporación de las artes plásticas iniciada en el Ministerio de Educación y Salud de Río de Janeiro. Pampulha constituye así una contribución significativa a la discusión sobre la síntesis de las artes que marcaría la arquitectura de la década de 1940.

A su manera, Pampulha — aún en su singular renovación morfológica - constituye una referencia al barroco minero que desde esos años se constituiría en modelo permanente de la arquitectura brasileña, y concretamente de Niemeyer. De este modo se inserta en un conjunto de exploraciones arquitectónicas que caracterizan la trayectoria del arquitecto.

Las dificultades con la jerarquía eclesiástica a la hora de consagrar la iglesia ponen de relieve hasta qué punto estas exploraciones características de los años de la Segunda Guerra Mundial y los que inmediatamente le siguieron, constituían el resultado de las convicciones de grupos acotados y no siempre comprendidos al interior de la Iglesia. Las dificultades del propio Le Corbusier con su proyecto para la-Sainte-Baume apuntan en una dirección similar.

La catedral de Brasilia, realizada años más tarde, parece concebida como una suerte de Sainte-Chapelle del siglo XX (Fig. 02). Su propuesta consiste en reducir la materia al mínimo y hacer de la transparencia el elemento protagónico. Incluso el ángel suspendido sobre la asamblea pareciera constituir una alusión contemporánea al gótico. Al volumen unitario de planta circular 

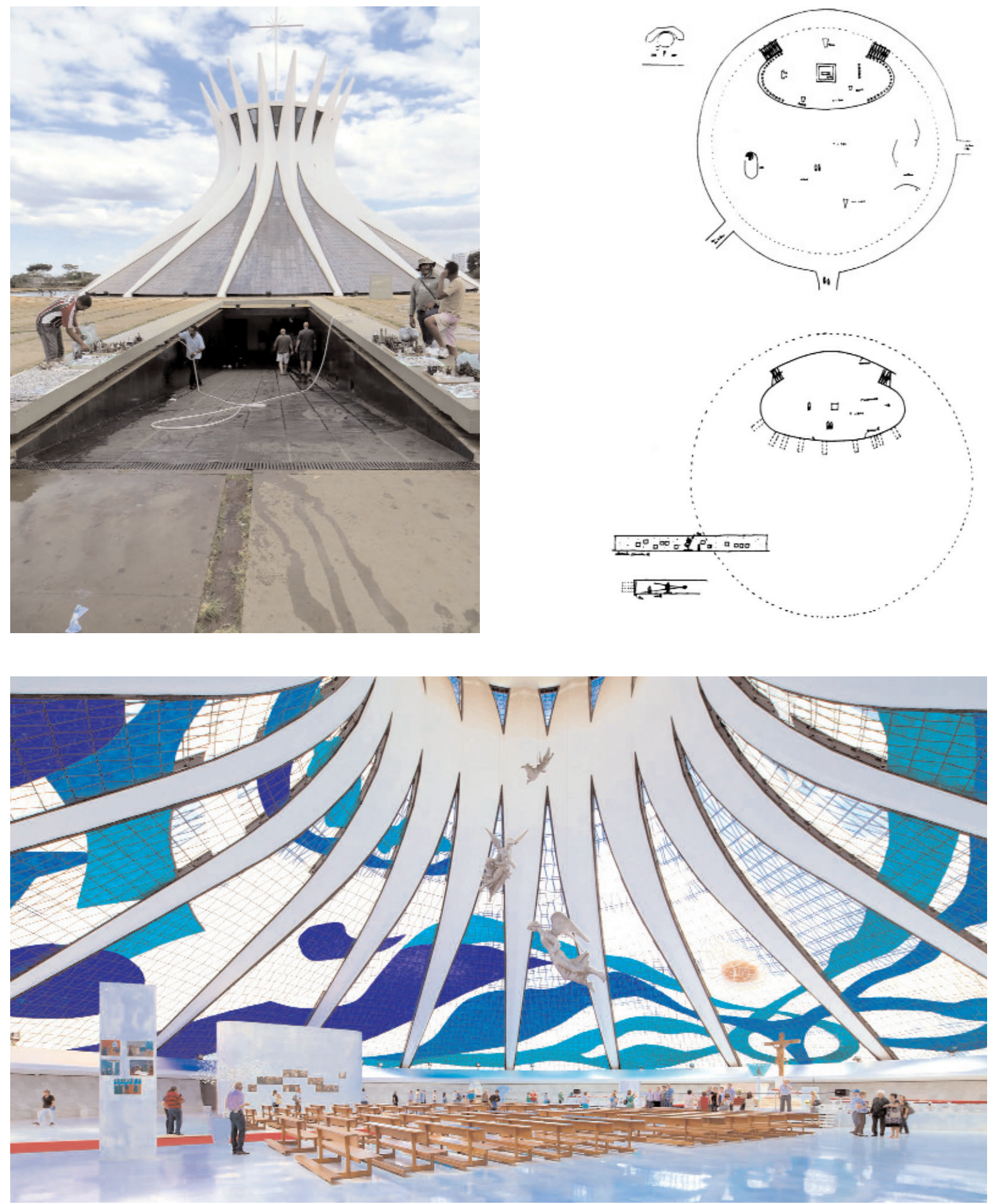

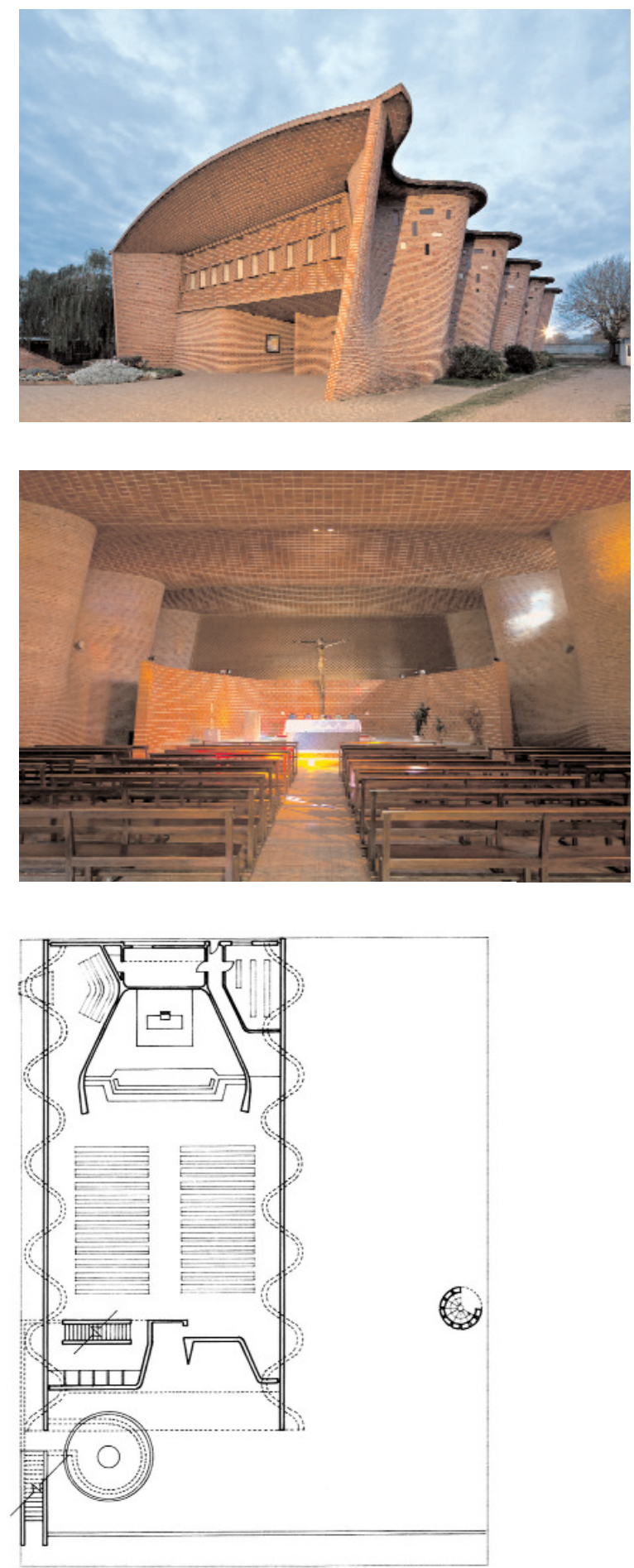

se ingresa desde el subsuelo, en una evidente búsqueda de la abstracción y de conservar la pureza del cuerpo geométrico que no quiere ser alterado ni siquiera por un acceso. Ello muestra la evolución de las ideas de Niemeyer desde Pampulha. La distribución de la asamblea en un pequeño sector de la planta genera una fuerte estetización de un espacio sagrado más concebido para ser contemplado y gozado que para cumplir las funciones pastorales y litúrgicas.

Tanto la iglesia de Cristo Obrero de Eladio Dieste en Atlántida, construida en 1952/60, como la capilla de Nuestra Señora de la Soledad en El Altillo de Coyoacán, de Enrique de la Mora y Felix Candela de $1955 / 57$, tienen un punto de arranque en la estructura, aunque ciertamente, ambas vayan más allá de ella.

La iglesia de Atlántida, que se levanta en una barriada de un balneario costero, propone una tensión entre innovación estructural y litúrgica (Fig. 03). En Cristo Obrero, Dieste pone la innovación estructural al servicio de la construcción de una iglesia con los medios económicos mínimos y que, por tanto, podía asociarse a un galpón o una nave industrial. Es el arte constructor de Dieste el que, a través de su precisión y del manejo de la luz, le aporta un carácter sagrado. El episodio del baptisterio junto al ingreso al que se desciende como símbolo del rito sacramental, pone de relieve la consciencia espiritual y litúrgica de Dieste.

En El Altillo (Fig. 04), De la Mora y Candela hacen que la cubierta parabólica cumpla múltiples funciones. Unifica el espacio interior cuadrangular ordenado por la diagonal y, a la vez que focaliza la atención sobre el altar, permite abrir una suerte de trascoro en el que se sitúan un notable conjunto de vitrales. El espacio litúrgico se hace a la vez sereno y dinámico, siendo capaz de construir una ordenación de la asamblea que deja el altar en una posición absolutamente central.

La iglesia de Nuestra Señora de Fátima, de Eduardo Ellis y Claudio Caveri (1956/58), está situada en el área norte de Buenos Aires (Fig. 05). Su comitente, el padre Fidel Horacio Moreno, tenía conexiones explícitas con el Movimiento Litúrgico. El proyecto es fruto de una reflexión antropológica muy consciente que, en el plano histórico, incluye la conexión de Claudio Caveri con Damián Bayón. Ello se hace evidente en la publi-

Fig. 02. Oscar Niemeyer, Catedral Metropolitana de Nossa Senhora Aparecida, Brasilia (Brasil), 1959/70.

Fig. 03. Eladio Dieste, Cristo Obrero, Atlántida (Uruguay), 1952/60. 

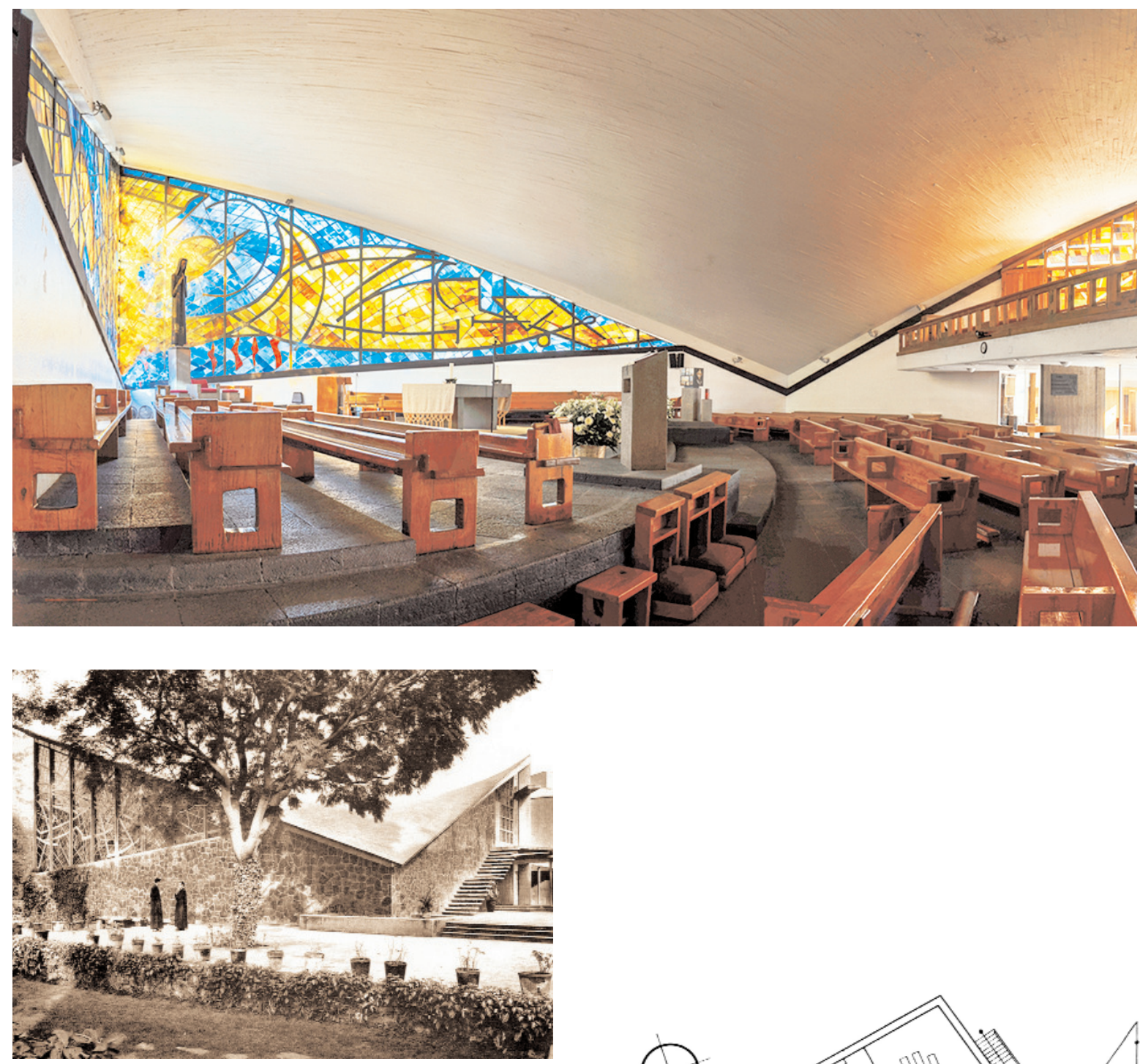

Fig. 04. Enrique de la Mora y Palomar y Felix Candela Outeiriño, Nuestra Señora de la Soledad del Altillo, Coyoacán (México DF), $1955 / 57$.

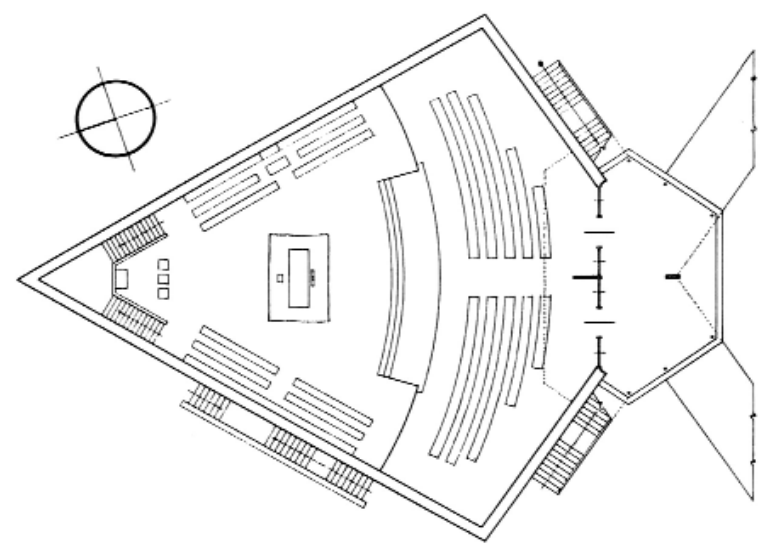


cación casi diez años más tarde de una serie de ensayos de Caveri bajo el título de El hombre a través de la arquitectura (1967). La iglesia se ordena a partir de una planta central en cruz griega, guiada por la luz que se mimetiza en una rica interrelación con los espacios exteriores y los recintos anexos. La reinterpretación de las iglesias coloniales altiplánicas que preocupaba a sus autores es evidente en los exteriores. Todo ello está acompañado por una espiritualidad del despojo que marca y enaltece el conjunto.

La capilla de las capuchinas de Luis Barragán, de 1959, parece haber sido un proyecto muy estimado por su autor, quien lo realizó motu proprio como una contribución al monasterio, tanto en lo que se refiere al proyecto como a su construcción (Fig. 06). Ella constituye una intervención de escala modesta al interior de un inmueble existente. La capilla puede ser descrita como un intento por compatibilizar la retención y minimalismo propio de una sensibilidad artística abstracta, con la tradición colonial local que tanto atraía a Barragán, en el contexto tradicional de una capilla conventual. Todos estos elementos se hacen presentes en el uso del color y en el protagonismo de la luz, fundamental en muchas de las iglesias y capillas latinoamericanas. Este esfuerzo de abstracción, geográfica y culturalmente localizada, se resume en el tríptico dorado situado tras el altar, fruto de la provechosa colaboración de Barragán con el artista de origen alemán Mathias Goeritz.

La iglesia del monasterio benedictino en Las Condes, Santiago de Chile, de Gabriel Guarda y Martín Correa - ambos benedictinos y arquitectos-, fue terminada casi juntamente con la clausura del Concilio, y resume bien algunas de las convicciones que primaron durante esos años en los círculos eclesiásticos culturalmente sofisticados (Fig. 07). Por otra parte, benedictinos es fruto de una larga historia comenzada con un concurso convocado diez años antes de su finalización en 1964. En ella se suceden diversos arquitectos, por lo que el proceso de proyecto resume, a su modo, algunas de las tendencias y tensiones de la arquitectura local. Recoge también la atención que Latinoamérica prestaba a algunas de las elaboraciones europeas contemporáneas.

En la matriz cúbica de la iglesia, comparece el precedente de la capilla de Pajaritos, de Alberto Cruz y la Escuela de Valparaíso (Fig. 08), pero en la ordenación de la doble asamblea de fieles y monjes parece haber
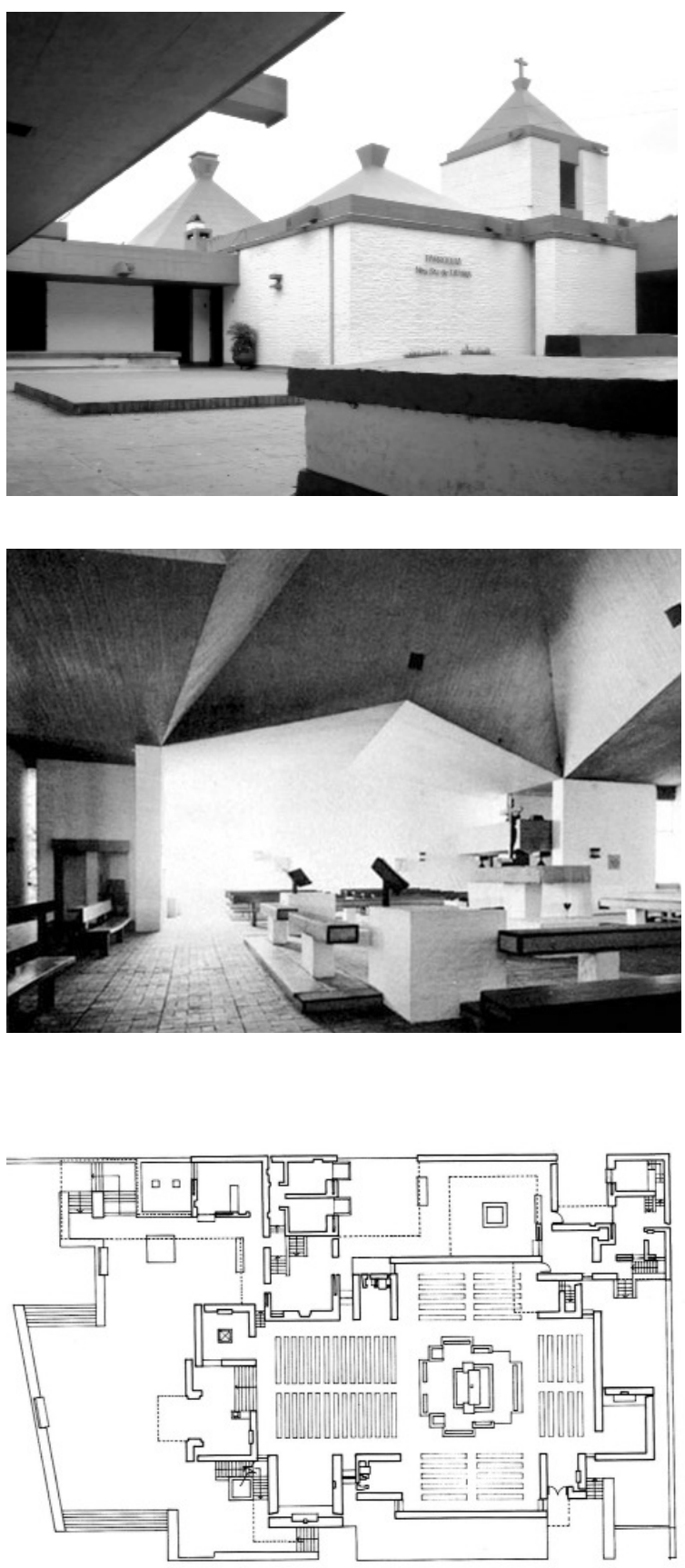

Fig. 05. Eduardo Ellis y Claudio Caveri, Nuestra Señora de Fátima, Martínez (Buenos Aires, Argentina), 1956/58. 
Fig. 06. Luis Barragán Morfín, capilla del convento de las Capuchinas Sacramentarias, Tlalpan (México DF), 1952/59.
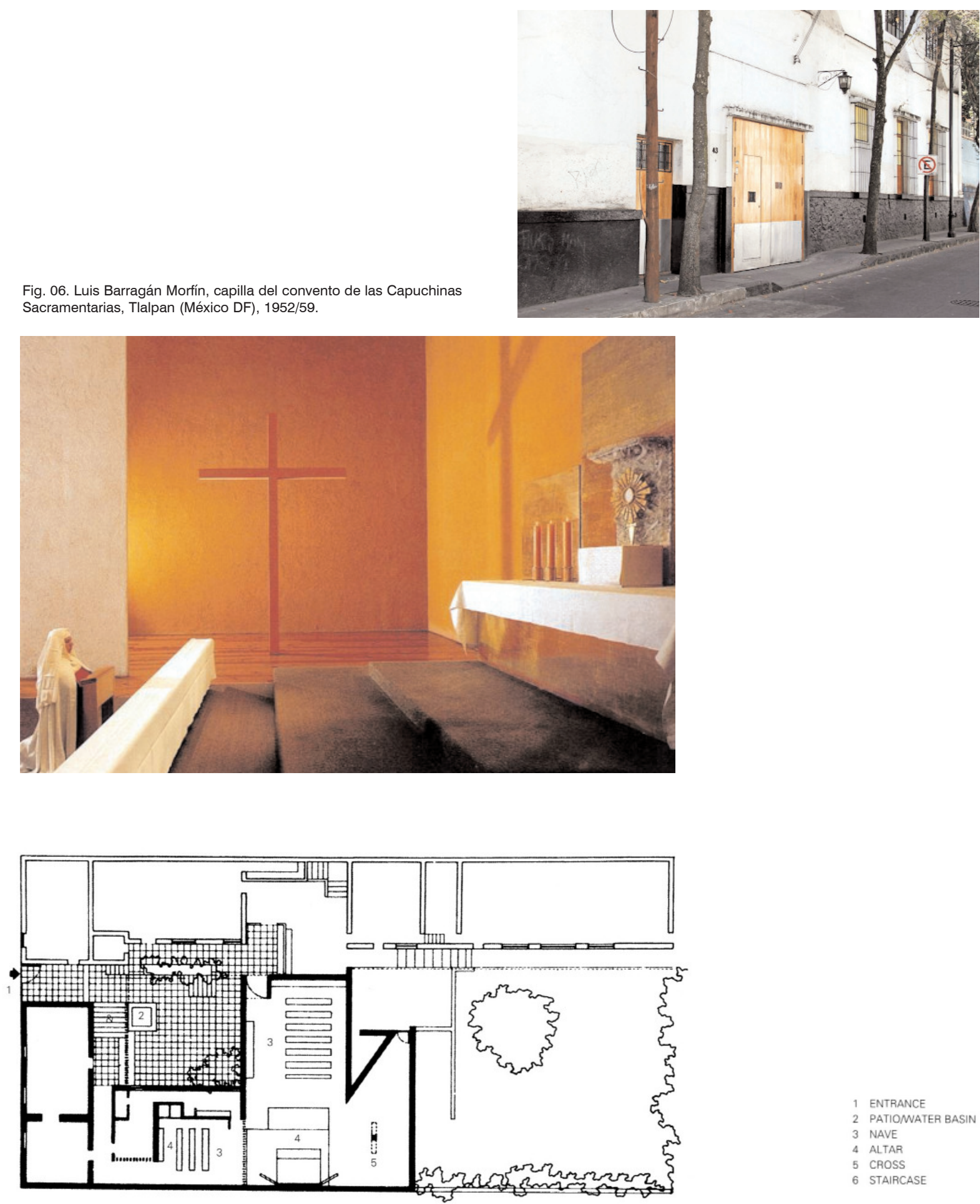

ENTRANCE

2 PATIONVATER BASIN

3 NAVE

4 ALTAR

5 CROSS

6 STAIRCASE 


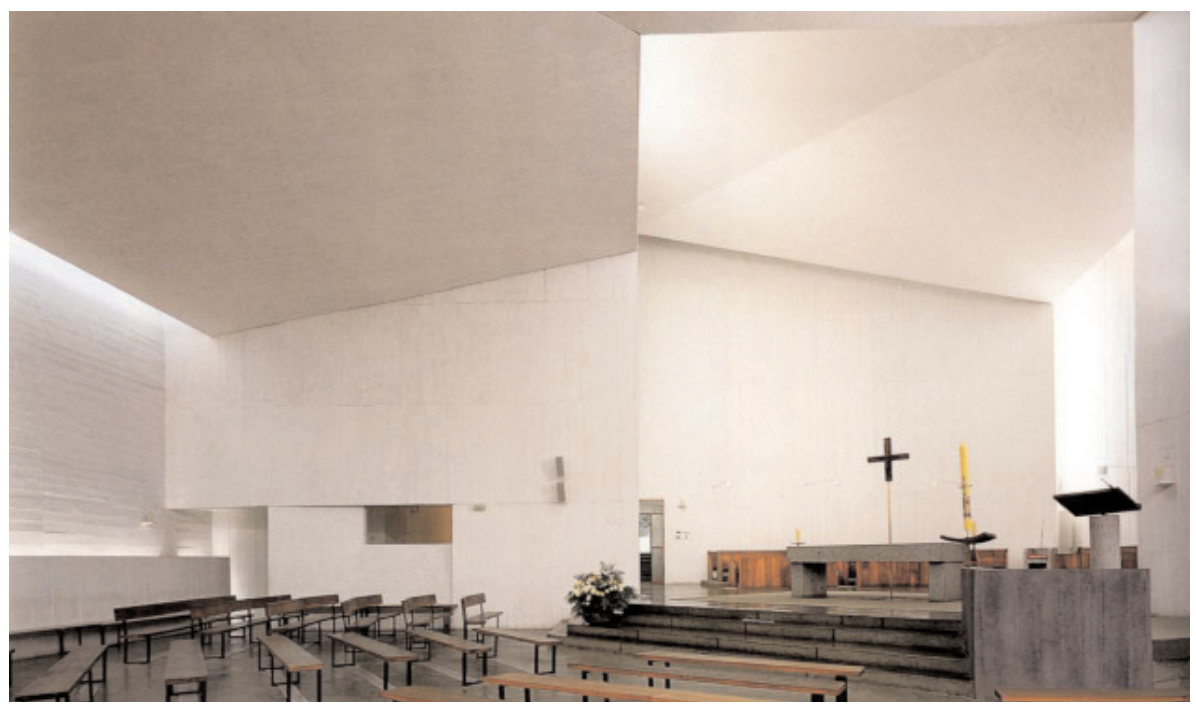

Fig. 07. Gabriel Guarda Geywitz y Martín Correa Prieto, osb, iglesia del Monasterio Benedictino, Las Condes (Santiago de Chile), 1962/64.
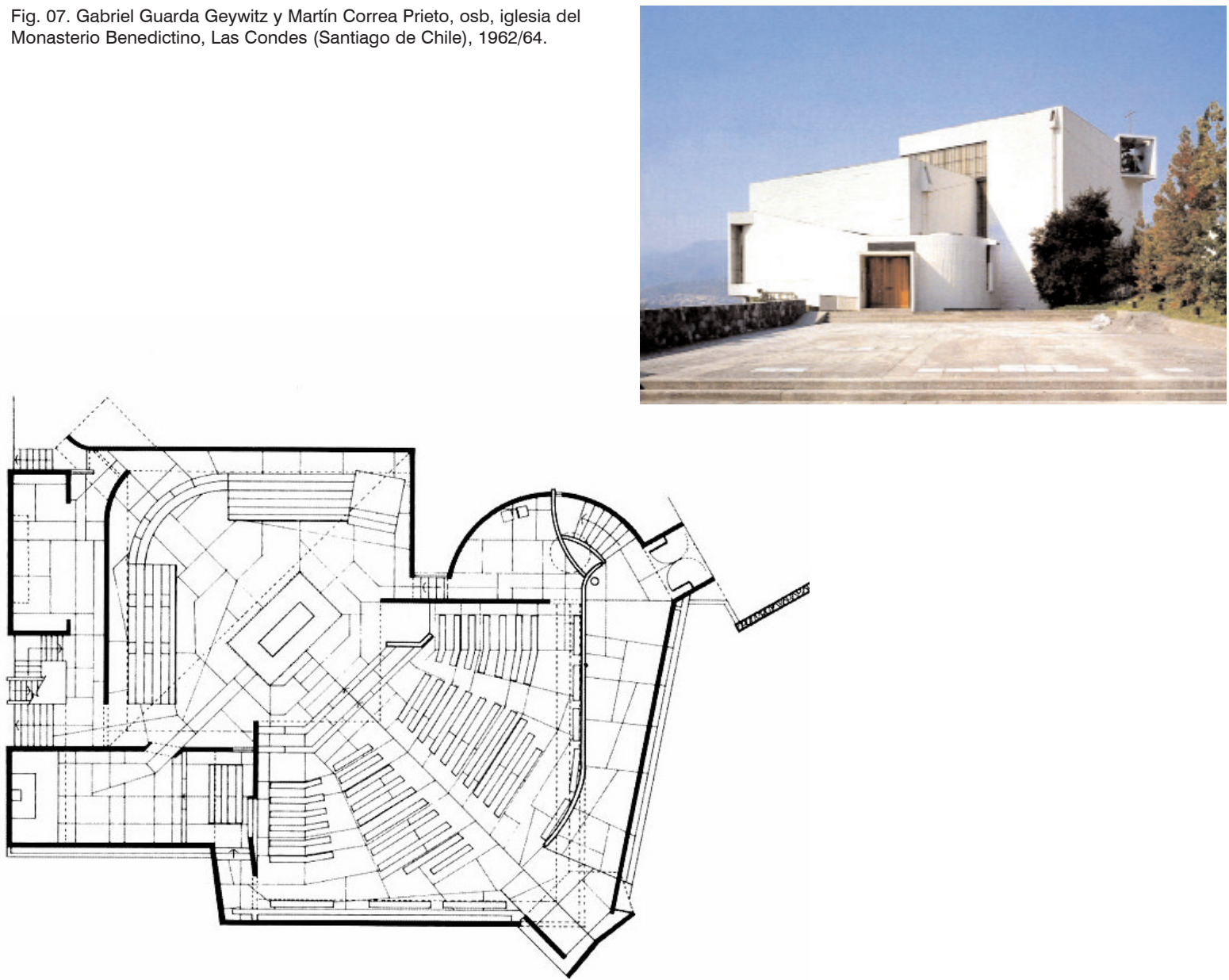

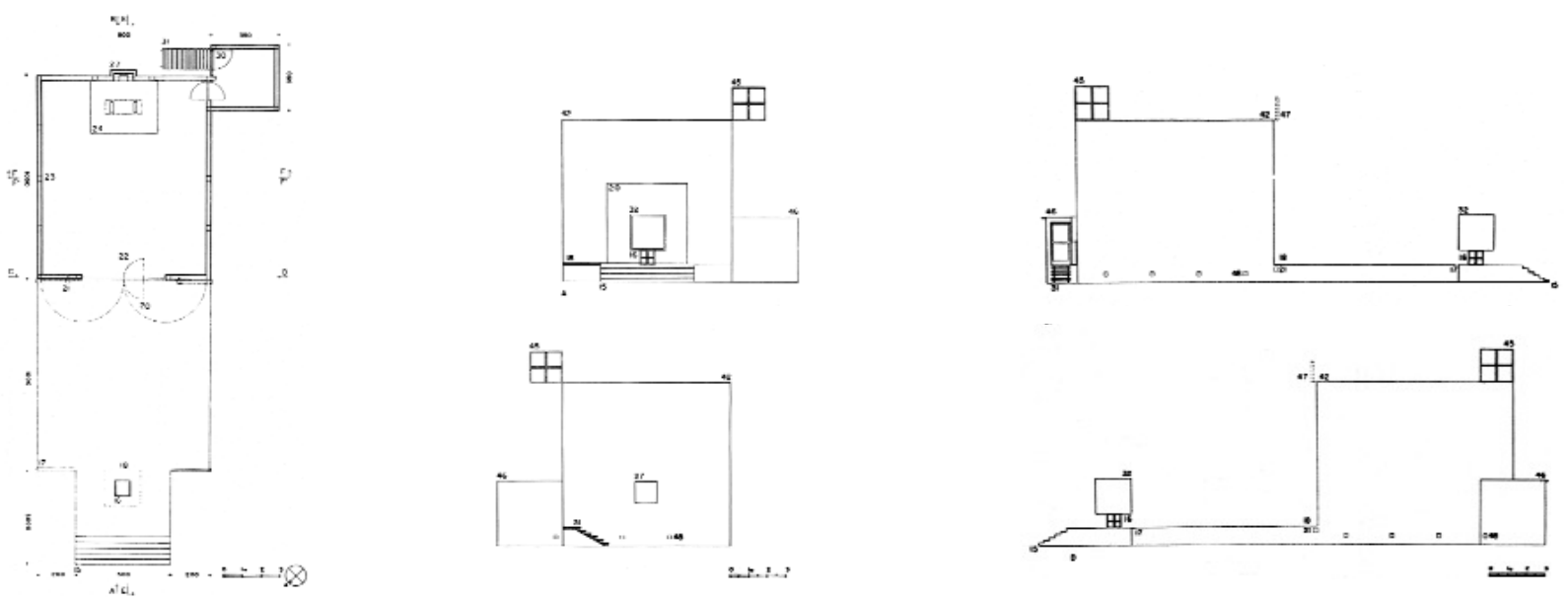

Fig. 08. Alberto Cruz Covarrubias y la Escuela de Valparaíso, capilla en el Fundo Los Pajaritos, Maipú (Chile), 1953; proyecto.

una referencia a la iglesia de San Pedro Mártir, de Miguel Fisac (Alcobendas, Madrid), terminada en 1960, y que uno de sus autores, Gabriel Guarda, había conocido en España. La matriz cúbica, el color blanco del hormigón y el protagonismo de la luz, parecen venir de Pajaritos, mientras que a San Pedro Mártir la relaciona la organización en planta de las dos comunidades enfrentadas.

Las estrechas relaciones de arte y arquitectura ya anunciadas por Portinari en Pampulha se prolongaron en la práctica latinoamericana. La colaboración de la gran escultora chilena Marta Colvin con su discípulo Francisco Gazitúa dio lugar a la notable imagen de la Virgen en madera que marca el acceso de la iglesia de Las Condes (Fig. 09). El artista Adolfo Winternitz, nacido en Viena, formado como vitralista en el Vaticano, convertido al catolicismo y finalmente residente en el Perú, representa magistralmente esta tendencia en Latinoamérica a mediados del siglo XX. Su obra alcanza una cima en los vitrales para la iglesia del colegio Verbo Divino, en Santiago de Chile (Fig. 10), que conviven con un notable Cristo del escultor Sergio Castillo.

\section{EL CONCILIO VATICANO II COMO CATALIZADOR}

En su constitución sobre la Sagrada Liturgia Sacrosanctum Concilium (1964), el Concilio Vaticano
II acogió algunas de las propuestas que venían siendo exploradas por el Movimiento Litúrgico; la celebración de cara al pueblo fue la más obvia de ellas. Sin embargo, la organización del presbiterio en torno a la triple polaridad de altar, ambón y sede constituye una novedad conciliar. El presbiterio se constituía así en la representación de Cristo como sacerdote, maestro y rey. Estos elementos provenían de la tradición de la liturgia romana, pero representaban un cambio muy sustantivo respecto a siglos de organización del presbiterio prioritariamente en torno al altar, así como en la supresión de la dualidad de epístola y evangelio y en la generalización del uso de la sede, anteriormente limitada a las cátedras episcopales. Incluso, tal propuesta se distanció de prácticas que venían siendo habituales en muchas de las iglesias concebidas de acuerdo a los principios del Movimiento Litúrgico. Tal es el caso de los enormes crucificados que solían presidirlas.

Dado que las iglesias debían acoger masivamente las nuevas normas litúrgicas, la necesidad de adaptarlas $-\mathrm{y}$ muy especialmente sus presbiterios- se tornó una cuestión central en todo el mundo católico. Latinoamérica no constituyó una excepción. Ello se aprecia en muchas catedrales latinoamericanas, donde por lo general, se verificó la adopción de las normas litúrgicas, especialmente el altar de cara al pueblo. Sin embargo, estas reformas no alcanzaron, por lo general, 


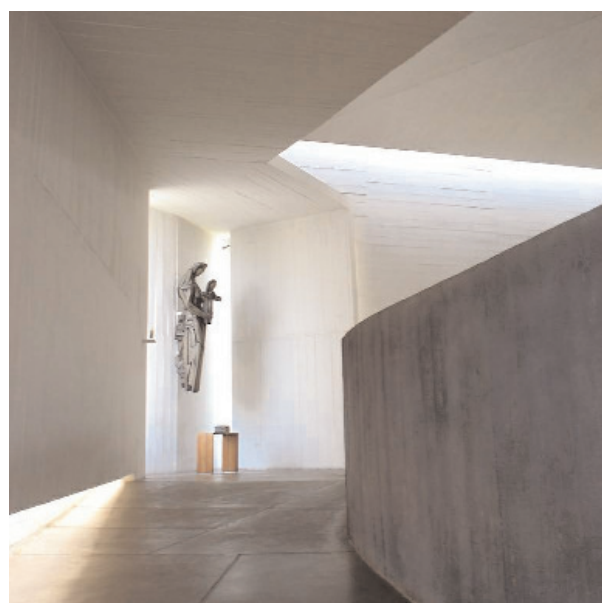

Fig. 09. Marta Colvin y Francisco Gazitúa, imagen de la Virgen en madera que marca el acceso de la iglesia de Las Condes, Santiago de Chile, 1970.

a constituir una reformulación del espacio sacro, cumpliendo de manera más bien literal con la norma.

Los cambios propuestos por la liturgia conciliar se cruzaron, por otra parte, con cuestiones de naturaleza diversa pero de consecuencias decisivas para la práctica diaria del culto y la organización de los templos. Véase, por ejemplo, la introducción de la amplificación acústica eléctrica que implicó, de hecho, la obsolescencia de los púlpitos, un elemento que había adquirido enorme importancia litúrgica y artística muchos siglos atrás. Esto coincidió con la inesperada expansión de la celebración en lenguas nativas, que prevista por la constitución con un carácter más bien excepcional, se constituyó, en un breve lapso de tiempo, en regla común alrededor del mundo. Tal práctica fue acompañada por una renovación musical no siempre afortuna$\mathrm{da}$, sin considerar - o considerando en una medida muy menor - la recomendación conciliar de continuar cultivando la tradición del canto gregoriano.

Probablemente, lo que resulta más definitivo acerca de las reformas en el periodo inmediatamente posterior al Concilio y muy especialmente en Latinoamérica, es su carácter masivo, que se separa claramente de los experimentos previos. No se trata de un rasgo meramente cuantitativo. En el período postconciliar, los cambios litúrgicos salieron del ámbito de los monasterios benedictinos y los círculos culturales sofisticados, para llegar a cada

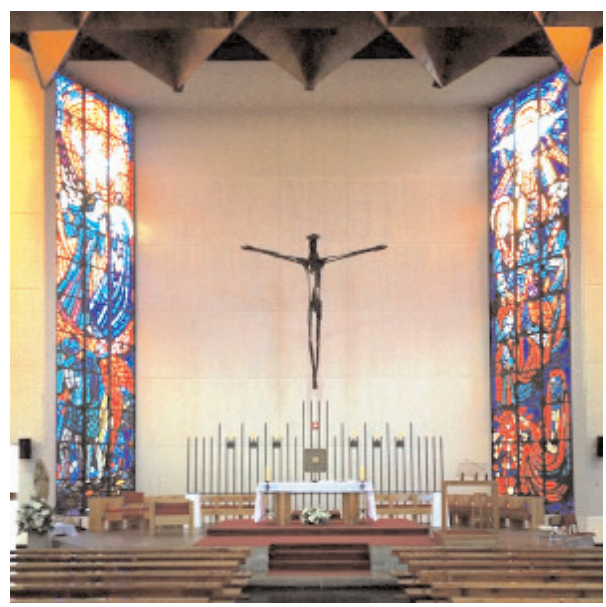

Fig. 10. Sergio Larraín, Emilio Duhart, Mario Pérez de Arce y Alberto Piwonka, capilla del Colegio Verbo Divino, Santiago de Chile, 1962. Cruz de hierro de Sergio Castillo y vitrales de Adolfo Cristóbal Winternitz.

modesta parroquia, que operó con los medios de que buenamente- disponía y con el grado de comprensión que cada cual logró tener de los cambios conciliares.

Las exploraciones acerca de posibles disposiciones de la asamblea que se desarrollaron en los años de la posguerra y adquirieron tanta importancia en algunas de las iglesias de la reconstrucción, no adquirieron la misma importancia en el postconcilio, en parte por razones prácticas: las iglesias y sus naves, casi siempre tradicionales, no admitían demasiadas adaptaciones. Pero ocurrió también que, en la medida que las nuevas practicas litúrgicas se masificaron, el entusiasmo por renovaciones más radicales disminuyó, hasta el punto de que no pocas veces llegó a surgir una nostalgia por las disposiciones tradicionales de las iglesias.

\section{LA TAREA DEL CONCILIO Y LA RESPUESTA LATINOAMERICANA}

Comparada con la vitalidad y calidad de algunos de los logros de los años previos al Concilio, uno estaría tentado de señalar que la producción de los años posteriores no alcanzó la misma intensidad ni la misma calidad. Al menos no hasta ahora. Esta es una hipótesis que, al menos, habría que discutir. Es difícil comparar un puñado de iglesias señeras, relativamente excepcionales, con una realidad masiva que tiene que habérselas con la vida cotidiana de toda una Iglesia. 

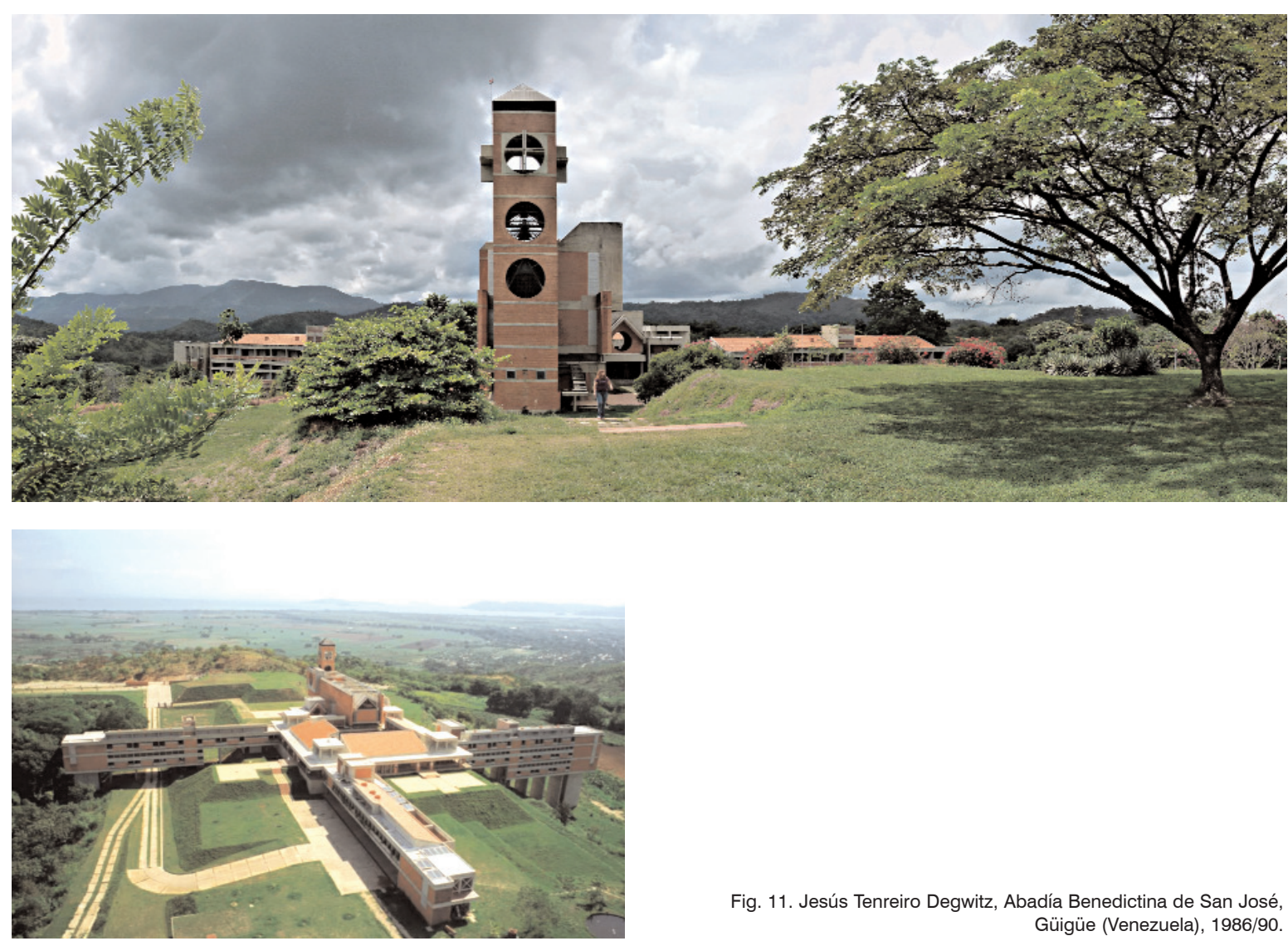

Fig. 11. Jesús Tenreiro Degwitz, Abadía Benedictina de San José, Güigüe (Venezuela), 1986/90.

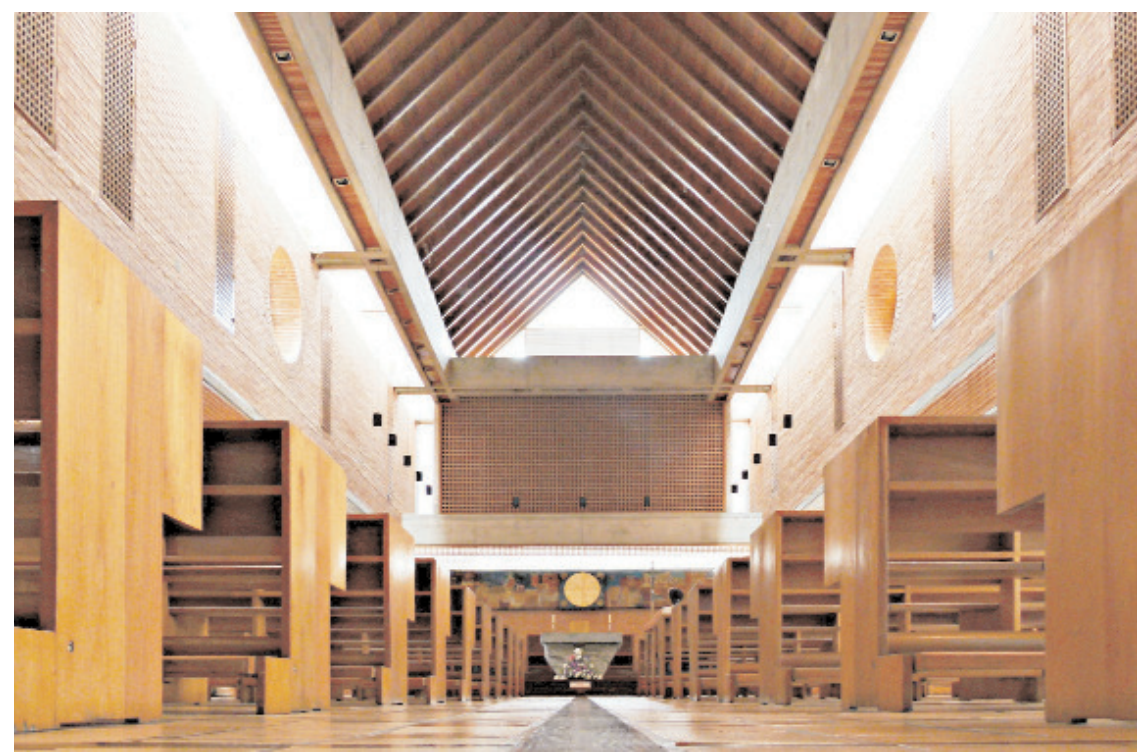


Sin embargo, es posible examinar algunos ejemplos cualificados, surgidos en ese contexto problemático a que el espíritu del Concilio Vaticano II ha debido enfrentarse. Ciertamente, las iglesias construidas en Latinoamérica en los años posteriores al Concilio no son exclusivamente el resultado de éste. Ellas representan el - a veces lento y no pocas veces difícil- proceso de asimilación de la teología conciliar, el diálogo con el estado de la arquitectura en la segunda mitad del siglo XX y los problemas de todo tipo - desde económicos a sociales y urbanos - que cada una de esas construcciones ha debido afrontar.

El monasterio de San José, de Jesús Tenreiro, construido en Güigüe (Venezuela) entre 1986 y 1990 (Fig. 11), es inseparable de esa mirada crítica sobre la arquitectura de vanguardia que se produce en la segunda mitad del siglo XX. La recuperación de la tradición y el diálogo con el pasado forman parte integrante de su programa arquitectónico. El monasterio comparte con el de La Tourette el desafío de asentarse en una topografía accidentada y el intento por repensar los límites del claustro, buscando una nueva relación de apertura con el contexto que lo rodea. Es este caso, un claustro central contraído está rodeado por un esquema de esvástica o molinete del que la iglesia forma parte, abierto a los cuatro puntos cardinales.

Más allá de ciertos rasgos kahnianos externos, como las ventanas circulares o los paños de albañilería confinados por un cuidado hormigón, resuena el esfuerzo - compartido por Kahn y Tenreiro- de reinterpretar la tradición. Ésta es superior a los intentos por dar con una nueva forma que reinterprete la liturgia. Con su planta longitudinal, esta iglesia propone una versión de gran calidad de esa actitud de vuelta a la iglesia de naves que se sustenta, por una parte, en una actitud menos entusiasta frente a las novedades litúrgicas, y por otra, en una nueva confianza acerca de las posibilidades que puede ofrecer la historia de la arquitectura.

La capilla abierta del cementerio de Ritoque (Chile) fue levantada por la Escuela de Valparaíso y el Grupo Ciudad Abierta alrededor del año 2000 (Fig. 12). Se encuentra en las cercanías de Valparaíso, en una suerte de campo experimental y bucólico en el que residen algunos de sus miembros, y donde la Escuela de Arquitectura realiza deporte, actos poéticos y experimentaciones constructivas. Más que como una construcción en sí misma, la capilla debe entenderse como

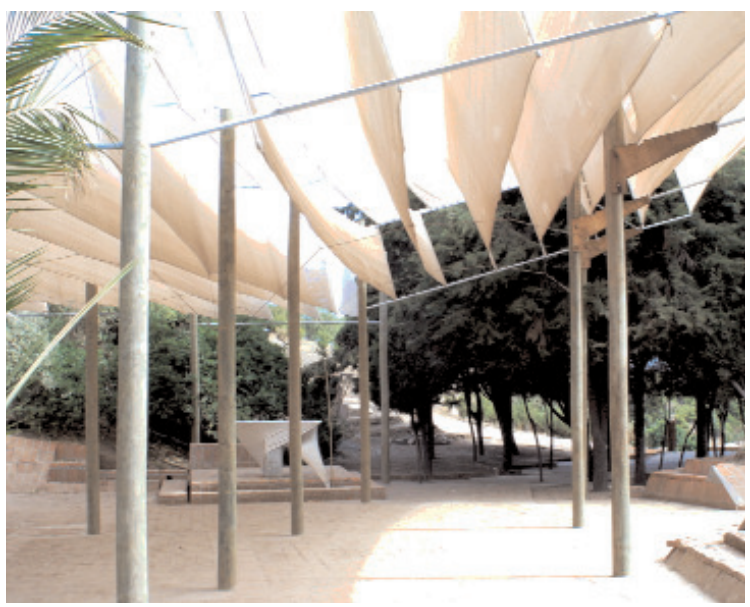

Fig. 12. Patricio Cáraves, Jorge Sánchez y Juan Purcell (Cooperativa Amereida), capilla abierta del cementerio, Ciudad Abierta de Ritoque (Chile), 1999.

una inflexión espacial en un contexto paisajístico mayor. Se genera, desde esta actitud, un espacio sagrado que es parte de un continuum en el que un cementerio, situado en el espacio lineal que sigue un curso de agua, remata en un anfiteatro al aire libre.

La capilla de Ritoque, más allá de prestar un servicio a los ritos y funciones propios de un peculiar cementerio, retoma el argumento de la capilla abierta, de tanta tradición en Latinoamérica, subrayando una continuidad entre naturaleza y espacio sagrado. Dada su situación y el contexto general de la Ciudad Abierta, la capilla ha sido planteada desde la intervención mínima y desde la ligereza, constituyéndose en una suerte de palio en el que un quiebrasol horizontal de tela interactúa con el altar y el espacio libre a su alrededor. Los asientos se disponen sólo durante las ceremonias. Esta capilla que da respuesta a condiciones contextuales y paisajísticas singulares, puede verse como un eco lejano de las iglesias que, cuarenta años antes, proyectó el mismo grupo en la zona sur de Chile, luego del terremoto de 1960.

La iglesia de Nuestra Señora de las Brisas (Fig. 13), ganada por concurso por Fernando Domeyko, fue realizada entre 1995 y 2010 cuando su autor era aún profesor del Massachussets Institute of Technology (Cambridge, EEUU). Inicialmente encargada como una pequeña capilla, acabó siendo una iglesia de tamaño significativo pro- 

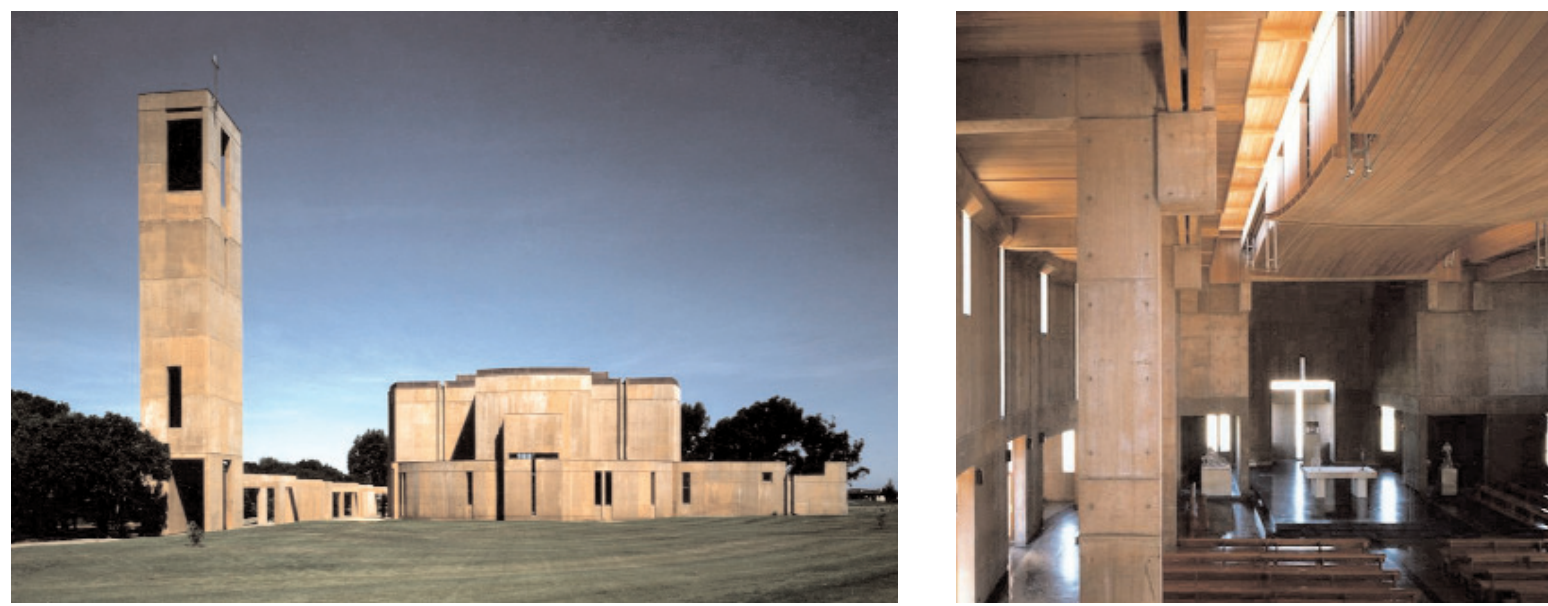

Fig. 13. Fernando Domeyko, Nuestra Señora de las Brisas, Santiago de Chile, 1995/2010.

Fig. 14. En la otra página: Rafael Moneo Vallés, Catedral de Nuestra Señora de Los Angeles, Los Ángeles (California, EEUU), $1996 / 2002$.

vista de algún equipamiento complementario, que sirve a un balneario de la zona central de Chile. A su manera, también esta iglesia busca un diálogo con la tradición, pero lo hace desde un aprecio por la arquitectura moderna tardía. Una cierta monumentalidad se pone de manifiesto en su masividad y en el cuidadoso uso del hormigón teñido. El campanario exento se combina con un recorrido longitudinal a la manera de un claustro extendido, que subraya la presencia de un antiquísimo bosquecillo de árboles nativos al que la iglesia se arrima.

La planta ovoide, elegida por sus condiciones estructurales — pero también por su alusión a una reunión alrededor del altar-, acomoda en su interior un esquema de crucero a través de la organización de la asamblea. Ésta combina la localización cercana al altar por tres de sus lados con una disposición axial tradicional que acentúa el sentido procesional. En el contexto de un balneario construido alrededor del campo de golf, profusamente ajardinado, la iglesia contrasta proponiendo un tono solemne e intemporal, opuesto a la arquitectura dominante, más bien informal, como la vida que allí se desarrolla.

Haciendo una excepción en este recuento, nos referiremos ahora a la catedral de Nuestra Señora de Los Angeles, de Rafael Moneo, inaugurada en 2002 (Fig. $14)$, teniendo en cuenta que, en cierto modo, una parte más que significativa de Los Ángeles puede verse como una extensión de la cultura latinoamericana. El caso es interesante, porque el problema de construir catedrales ha sido una de los más complejos de la arquitectura eclesiástica y no ha resultado sencillo de resolver en los años a que nos referimos. El problema de la catedral de Los Ángeles no surge solamente de su funcionamiento interior, sino muy especialmente de su localización urbana junto a una autopista y de la intención de generarle un entorno propio con suficiente autonomía.

El segundo problema fundamental en ésta y en otras catedrales de su tipo es el manejo de la escala. Las grandes catedrales históricas no tenían habitualmente el objetivo de hacer participar a los fieles, y ciertamente, no es igual de sencillo agrupar los fieles en torno al altar de una pequeña capilla que en una nave única de grandes dimensiones, donde la relación entre el ámbito del fiel y la totalidad del espacio tiende a diluirse.

El diálogo de esta iglesia con la tradición se produce en términos peculiares. Por una parte, el ambiente de la nave, concebido como reunión en torno al altar, remite a la sensibilidad del confort en la oración, que resulta del tratamiento de los materiales y la luz, que tanto debe a las experiencias escandinavas. Por la otra, el recorrido de acceso a la iglesia se produce a través de un espacio en el que se suceden una serie de capillas que, en conjunto, operan como la inversión de una nave lateral tradicional. 

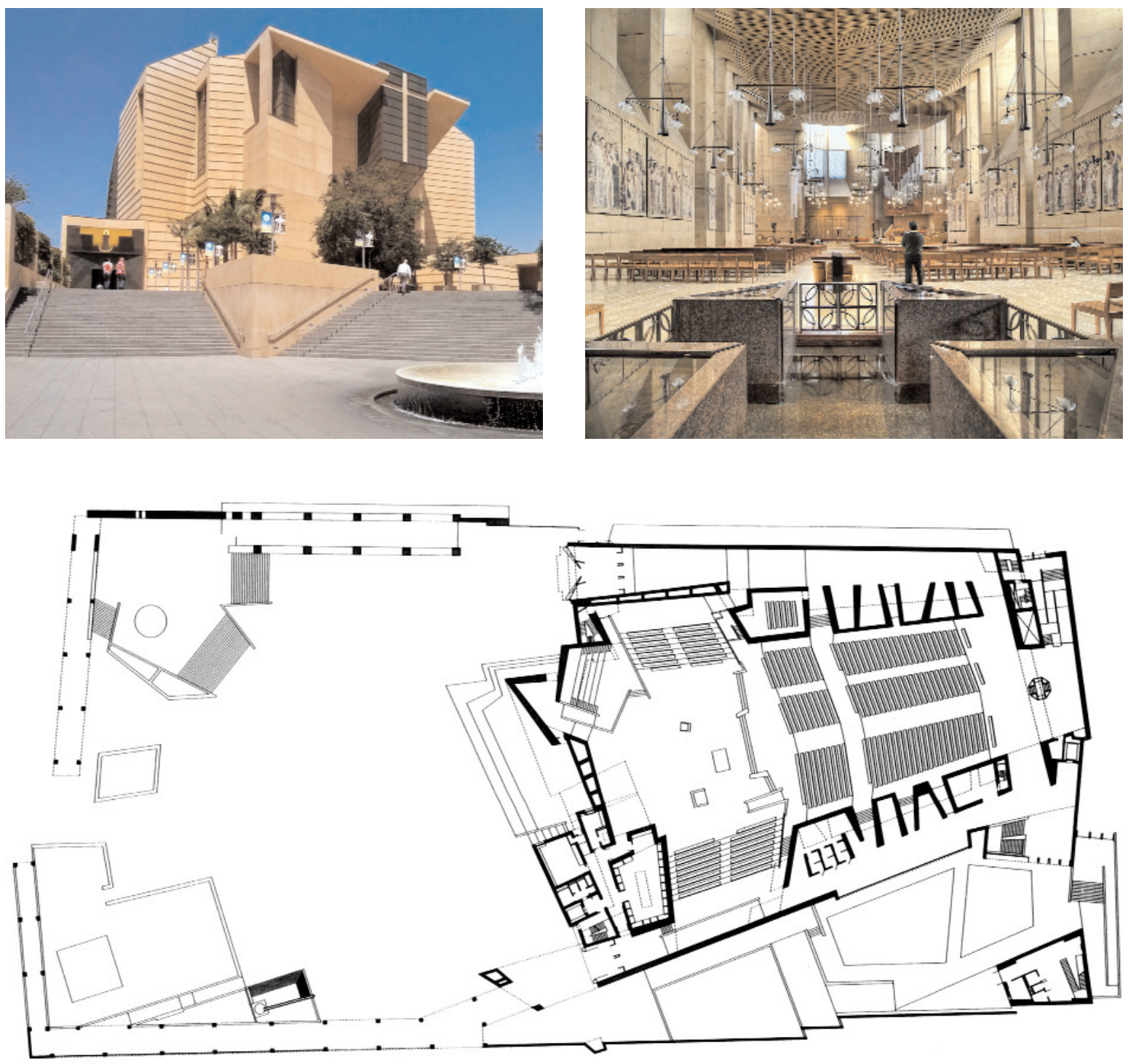

La relación con las obras de arte es otro dilema de los planteados por esta catedral. Las exploraciones del Movimiento Litúrgico estuvieron acompañadas de una simpatía por el arte moderno. Sin embargo, éste no siempre logró conquistar a los clérigos, a los fieles o incluso a la jerarquía, tornando problemática la relación entre la calidad del arte y su expresividad y funcionalidad en términos pastorales. Las catedrales solían ser obras relativamente colectivas, desarrolladas en plazos largos y que en algún sentido se concebían como infraestructuras que tenían la capacidad de recibir intervenciones artísticas de todo tipo. Esto es difícil de compatibilizar con una idea de autoría y con la coherencia interna que habitualmente se pide a la arquitectura contemporánea.

Javier Sordo Madaleno Bringas ha levantado en 2008 la iglesia dedicada a san Josemaría Escrivá en Santa Fe, un nuevo sector de Ciudad de México (Fig. 15). Ésta expresa una tensión entre una disposición tra- 

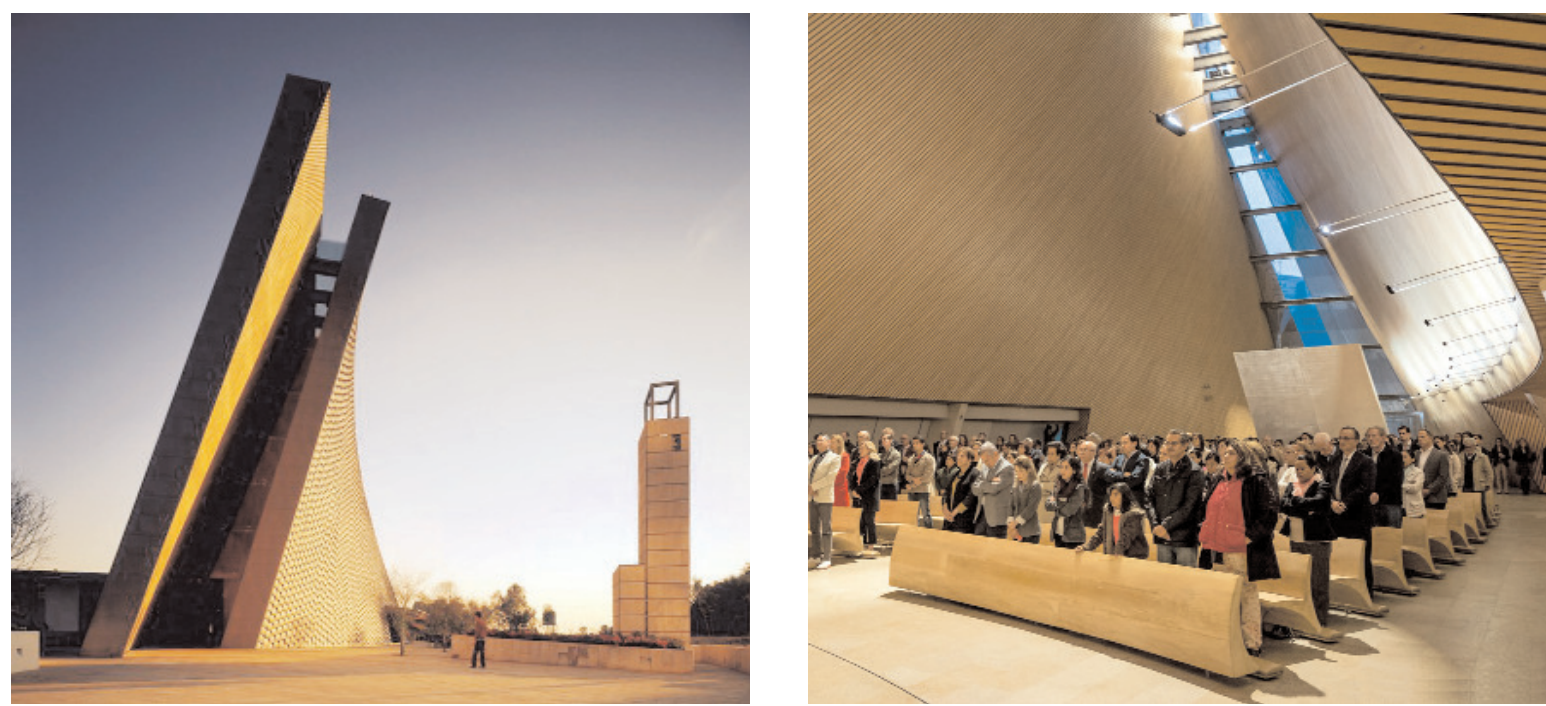

Fig. 15. Javier Sordo Madaleno Bringas, San Josemaría Escrivá, Santa Fe (México DF), 2005/08.

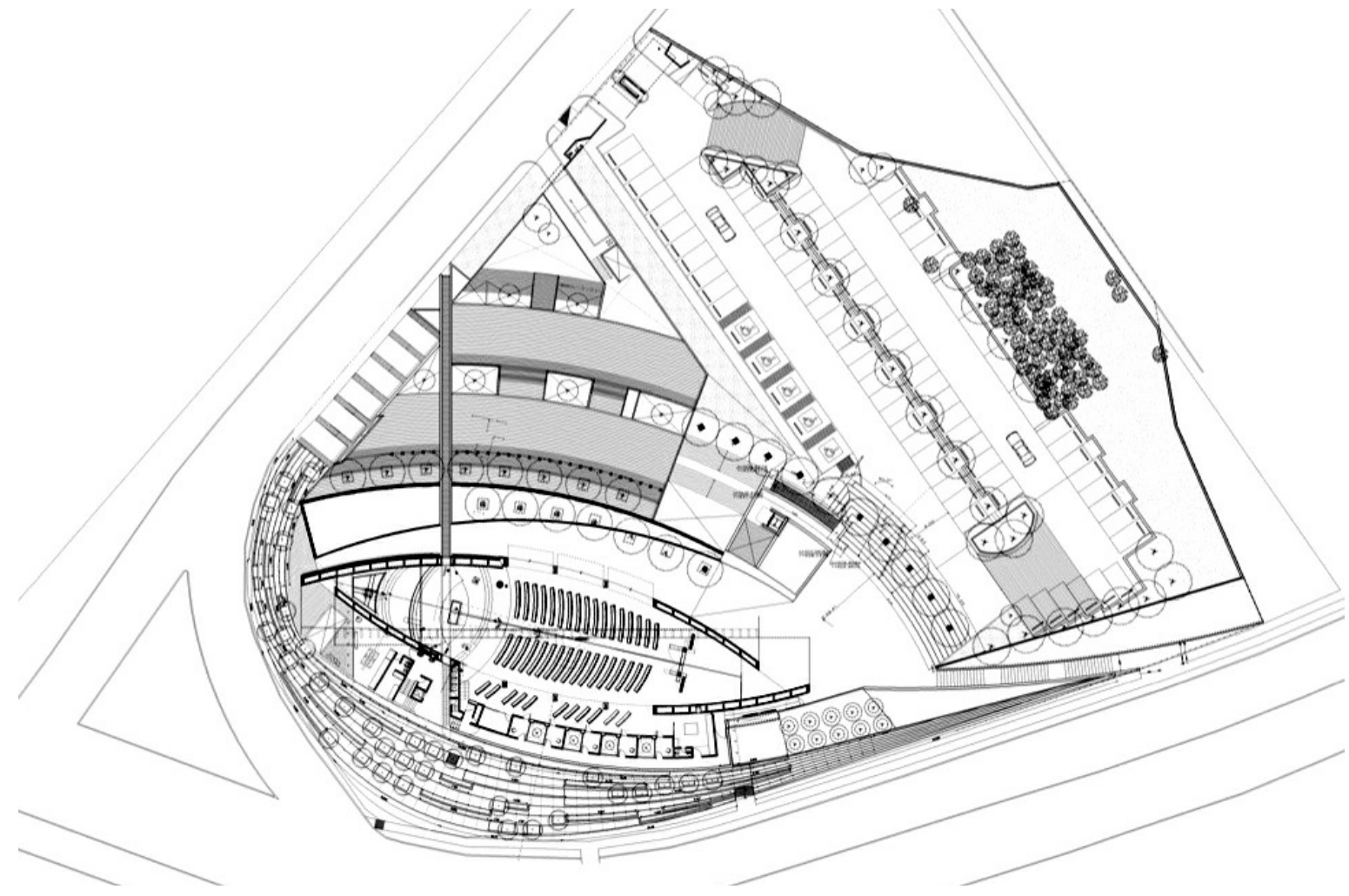


dicional y un movimiento ascensional — símbolo de oración y espiritualida, al menos desde el gótico-, y un virtuosístico ejercicio geométrico que relaciona de manera fluida el interior y el exterior. La valoración de la complejidad geométrica, acompañada de cierta riqueza de materiales y una actitud orgánica, parece verse como la adhesión a un espíritu de contemporaneidad arquitectónica. Ésta es puesta en relación con una nave longitudinal, de pasillo central y gran serenidad de disposición.

En las antípodas - por contexto y por sensibilidad arquitectónica - se encuentra la capilla irónicamente denominada Church(ita), proyectada por miembros del colectivo Supersudaka - concretamente por Juan Pablo Corvalán y Gabriel Vergara- en 2009 (Fig. 16). Localizada en un área periférica de Talca, ciudad intermedia de la zona central de Chile, esta capilla responde a la necesidad de un equipamiento religioso mínimo que, frecuentemente, debe servir también a otros propósitos. De hecho su interior puede extenderse fácilmente hacia el exterior, ampliando de este modo su capacidad.

Concebida como una suerte de caparazón, ligeramente elevada del suelo, el volumen se propone, por una parte, integrarse a la informalidad constructiva que domina el sector, a la vez que resistir los embates, no siempre amables, que sufren espacios y edificaciones públicos. En ella tiende a anularse la distinción entre muros y cubierta a través de una piel tratada como mosaico en la tradición del trencadís catalán. Sin embargo, tras esta aparente informalidad se esconde una planta regular, ordenada a partir de la diagonal de un cuadrado que recuerda esquemas frecuentes en los años del Concilio. El interior está definido por sus autores como «dominado por una luz de esperanza». Dicha luz, que ingresa indirectamente, brilla en medio de un difícil entorno.

Un reciente concurso organizado entre los estudiantes de la Universidad Católica de Chile, muestra la continuidad e importancia de esta temática que tiene fuertes componentes económicos y sociales. Se trataba de elegir un prototipo, a fin de construir, con la participación de los propios estudiantes, cincuenta capillas en zonas periféricas de diversas ciudades chilenas (Fig. 17). A pesar de ser, ciertamente, un concurso de estu-

Fig. 16. Juan Pablo Corvalán y Gabriel Vergara (Supersudaka), capilla de Cristo Salvador «Church(ita)», Talca (Chile), 2008/09.
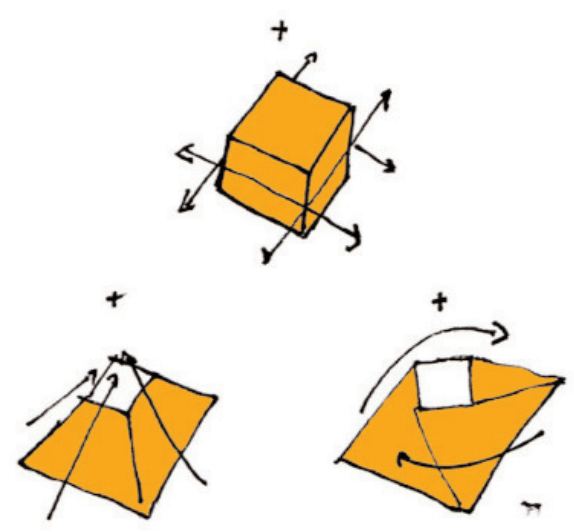

Twist.
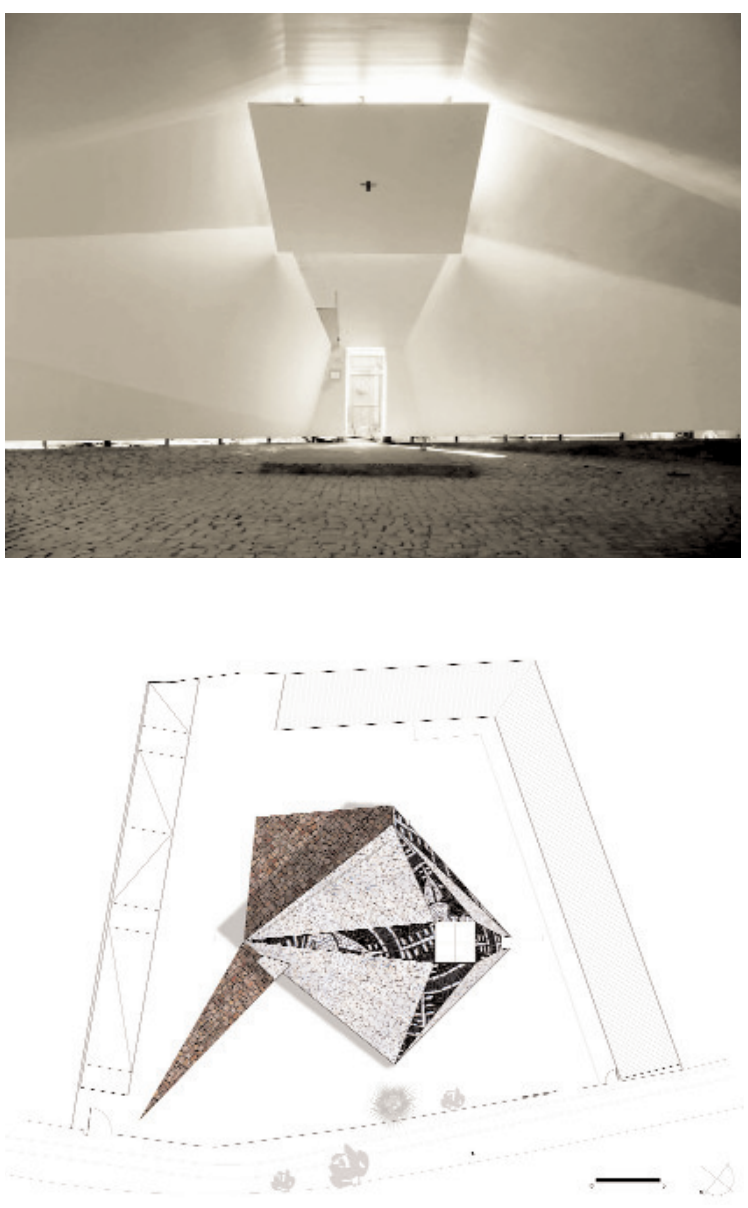

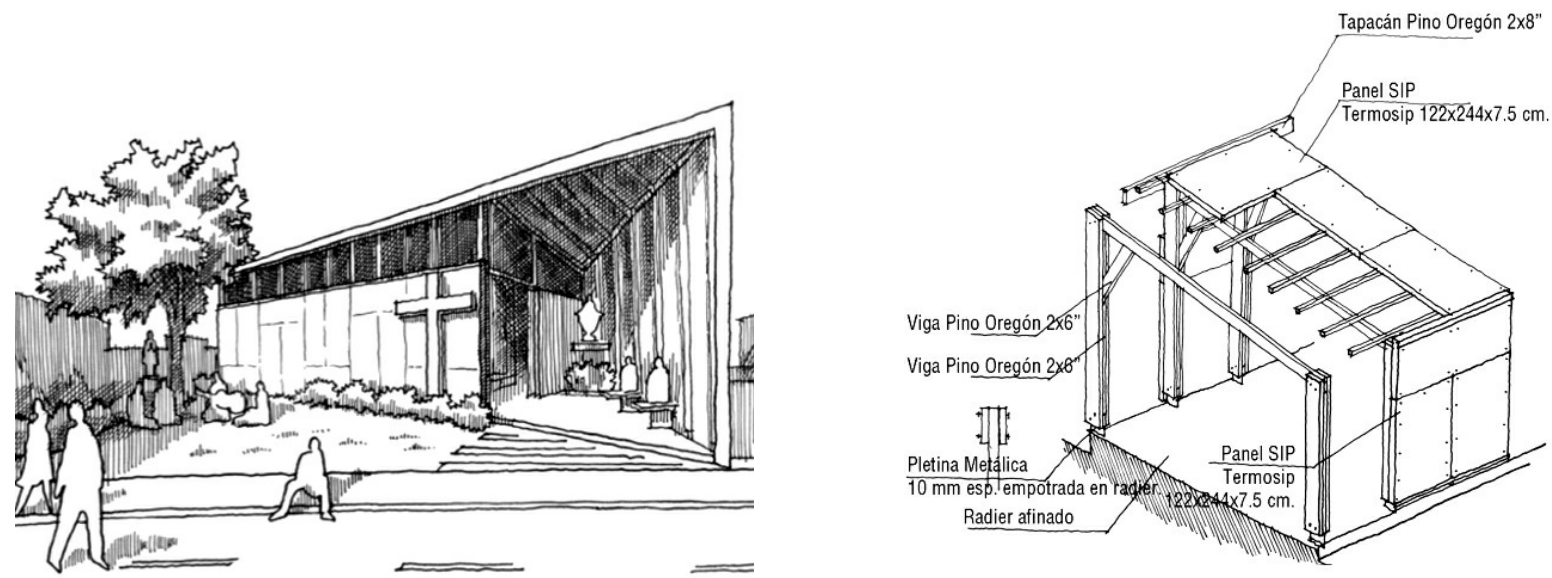

Fig. 17. Estudiantes de la Universidad Católica de Chile, «Capilla-país», 2014. Concurso de prototipos.

Fig. 18. María Eduarda Vieira, Santuario do Pai das Misericordias, Cachoeira Paulista (Sao Paulo, Brasil), 2008/14.
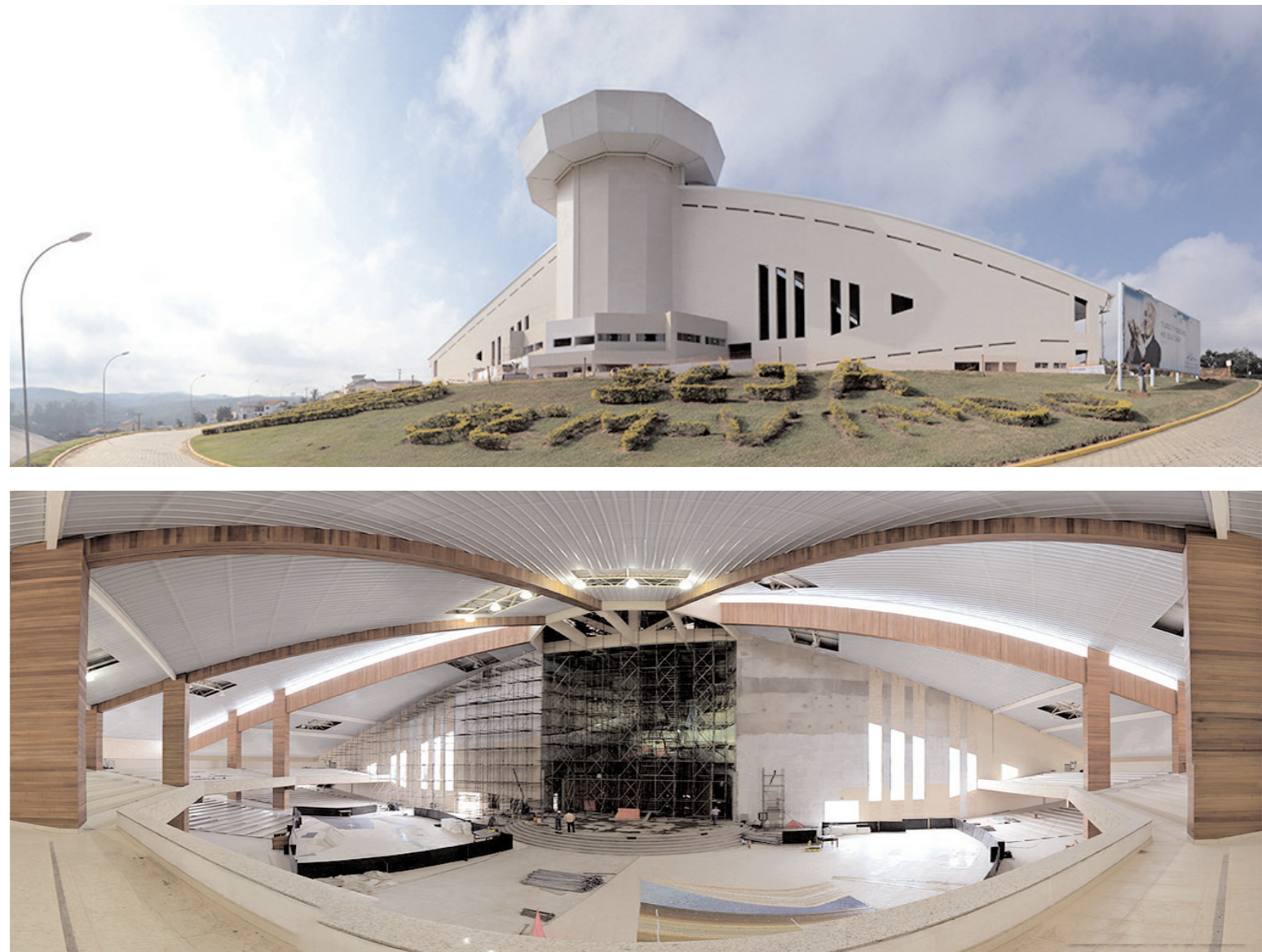
diantes con todas sus posibles limitaciones, se apunta a una problemática real de muchas ciudades latinoamericanas. La solución, en madera, es elemental en términos espaciales y constructivos, y casi podría definirse como la provisión de un mínimo recinto sacro.

La variedad de problemas enfrentados por la pastoral contemporánea se hace evidente en un caso como el santuario do Pai das Misericordias, proyectado en el área de Sao Paulo por María Eduarda Vieira (Fig. 18). El santuario responde al fenómeno masivo de la pastoral ligada a la música que se produce en Brasil, y se propone acomodar a cinco mil fieles según la creciente tendencia del turismo religioso. El delicado límite entre asamblea de fieles y público, y entre espacio litúrgico y teatro, se hace presente en un fenómeno contemporáneo como éste, proponiendo difíciles desafíos a su tratamiento arquitectónico.

Contrasta con esta realidad la Capilla de la Piedra, en Lima, de Ximena Alvarez y Nomena Arquitectos (Fig. 19). De escala casi familiar, esta pequeña capilla extensible construida en 2010, parece continuar las exploraciones del siglo XX en torno a las relaciones entre la arquitectura religiosa y el espacio sagrado. El cuidadísimo hormigón se pone aquí al servicio de un espacio silencioso que se extiende a sus alrededores a través de una serie de recintos, a la manera de un templo clásico. El esquema en espiral recuerda la propuesta de Niemeyer para la capilla del palacio de la Alborada, en Brasilia, y contribuye a su inserción en el contexto paisajístico.

La Capilla del Retiro, de Cristian Undurraga (Fig. 20), resultó hace poco una de los finalistas para el mejor proyecto de las Américas en el concurso MCHAP, convocado por IIT de Chicago - compitiendo con arquitectos de la talla de Álvaro Siza, Smiljan Radic o Rafael Iglesia-, y fue la vencedora del $V$ Premio Internazionale di Architettura Sacra Frate Sole (Pavia, Italia, 2012). Ello habla de la permanencia de las conexiones entre el tema de lo sacro y la arquitectura de calidad. Proyectada entre 2009 y 2012 en un paraje y unas condiciones privilegiadas, se trataba de proveer de capilla a una casa de retiros inserta dentro de un santuario dedicado a Juanita de Los Andes - santa recientemente canonizada-, situado en el extremo sur del hermoso valle del río Aconcagua, en Chile.

Como todos los santuarios que han proliferado en los últimos años, se trata de un lugar muy concurrido,
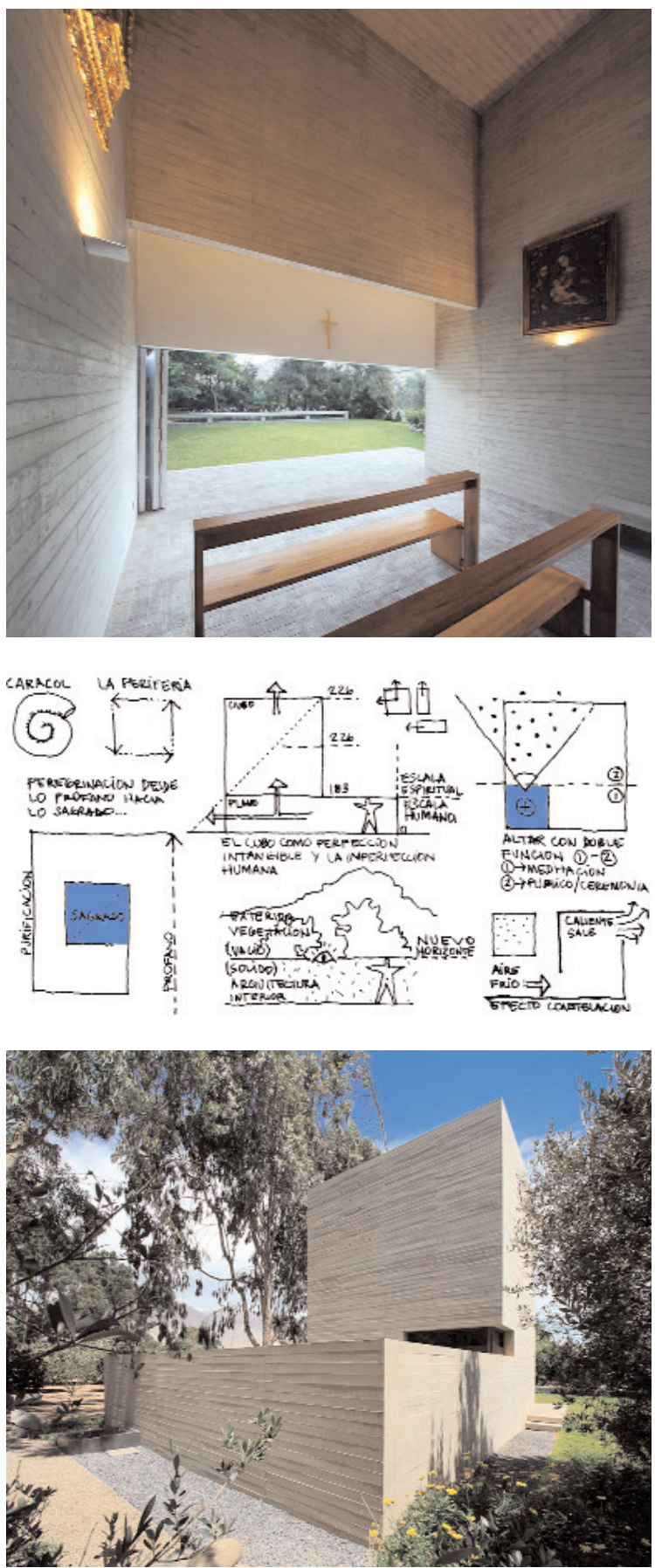

Fig. 19. Ximena Alvarez y Nomena Arquitectos, Capilla de la Piedra, Cieneguilla (Perú), 2009/10. 


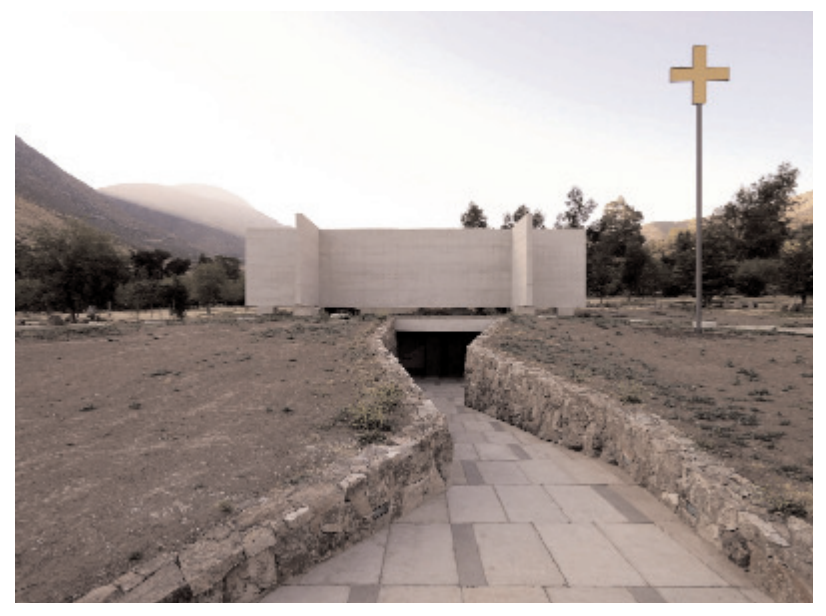

Fig. 20. Undurraga Deves Arquitectos, Capilla del Retiro, Valle de Los Andes (Chile), 2009/12.
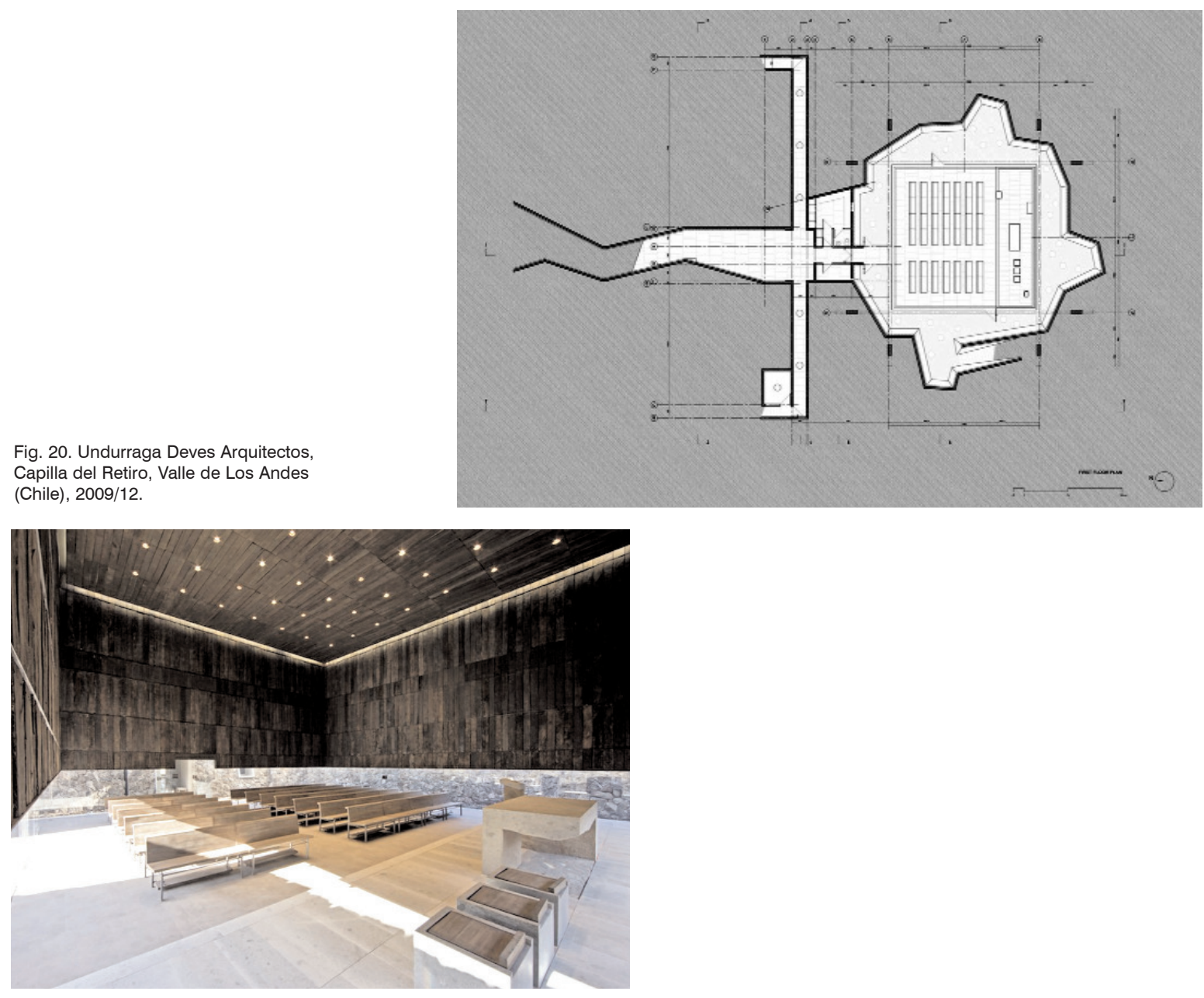
en actitudes que entremezclan la peregrinación y el paseo familiar. Para el núcleo inicial del santuario se escogió una arquitectura que rememora más o menos literalmente la construcción colonial. Situada en un lugar apartado del núcleo principal del conjunto, en que la presencia del paisaje y especialmente de las montañas vecinas es imponente, Undurraga asume una actitud completamente diversa. Concebida como una cripta situada, por tanto, bajo el nivel del suelo, la capilla aparece al exterior como un signo casi totalmente abstracto: un cuadrilátero de hormigón posado sobre el suelo. Como en la catedral de Brasilia, para acceder se debe descender por una rampa. El espacio interior, de gran quietud, se muestra como un cubo opaco suspendido y revestido en madera. La luz penetra por los bordes transparentes que llevan el límite de la nave — más allá del espacio interior - a una topografía artificial creada por el hundimiento de la misma. Las contribuciones al presbiterio, obra del escultor José Vicente Gajardo, contribuyen a dar densidad y calidad al conjunto.

\section{CONCLUSION}

Más que como un conjunto de instrucciones o de normas, la herencia del Concilio Vaticano II debería entenderse como una intención de renovación radical del espíritu de la Iglesia, a fin de devolverla a sus fuentes más auténticas. En tal contexto, las propuestas del Concilio han requerido un largo proceso de asimilación que, tal vez, diste mucho de haber finalizado. A cincuenta años de su clausura, tal vez estamos aún distantes de haber extraído las necesarias consecuencias de sus ideas y, menos aún, de haberlas encarnado debidamente.

Así ocurre con la nueva liturgia consagrada por los padres conciliares. Si bien es cierto que los cambios fundamentales a la liturgia ya se han extendido alrededor de mundo, ella no siempre se ha encarnado con la profundidad debida en cada uno de los rincones en que se produce la oración o se celebran los sacramentos.

En cierto modo, las normativas conciliares parecen haber paralizado o ralentizado el activo proceso de reflexión e intercambio que se produjo entre teólogos, liturgistas, arquitectos y artistas en las décadas previas al evento conciliar. A la luz de las directrices conciliares, tal tarea podría y debería resultar fructífera, para lograr encarnar con rigor y creatividad las propuestas del Concilio.
Sin embargo - y como se ha intentado mostrar previamente - en lo que hace a la construcción de nuevas iglesias, dicha tarea no debería incluir solamente las dimensiones litúrgicas del problema. Siendo fundamentales, éstas no agotan sus múltiples dimensiones.

Las nuevas iglesias que se levanten en el siglo XXI deberían considerar las ideas del Concilio como una totalidad articulada. Así, la constitución Sacrosanctum Concilium debería dialogar con otras tan importantes como Lumen Gentium o Gaudium et Spes, ya que los templos que levantemos serán, a su manera, sacramentos de la presencia de la Iglesia en el mundo.

En cualquier caso, sería fundamental volver a provocar ese diálogo con artistas y constructores que en otros momentos resultó tan productivo. Las iglesias no han surgido ni surgirán como entidades abstractas provenientes de un conjunto de normas. Ellas deberían ser el resultado de una nueva espiritualidad en diálogo con la cultura y con las variadísimas circunstancias culturales y pastorales en que cada nueva iglesia se inserta. Las reflexiones específicas de la arquitectura sobre estos problemas, en este nuevo siglo que nos toca vivir, debieran realizar una contribución más que significativa a esta tarea.

\section{PROCEDENCIA DE LAS ILUSTRACIONES}

Todas las imágenes pertenecen al archivo del autor, salvo las siguientes:

Fig. 06b. Armando Salas Portugal.

Fig. 07a/b y 09. Roland Halbe.

Fig. 11a. Liborio.

Fig. 12. Cooperativa Amereida.

Fig. 19. Ximena Alvarez y Nomena Arquitectos.

Fig. 20. Undurraga Deves Arquitectos. 